
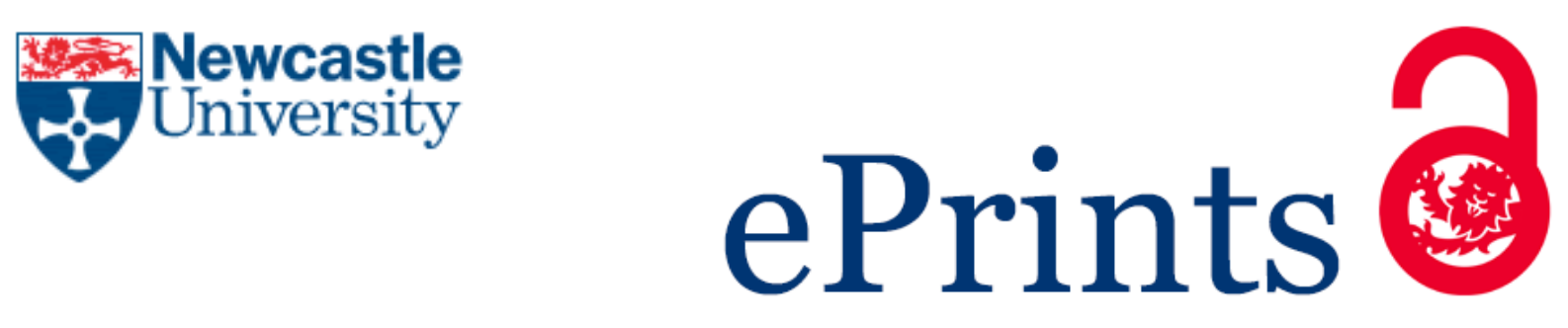

\author{
Ventura C, Guerin AJ, El-Zubir O, Ruiz-Sanchez AJ, Dixon LI, Reynolds KJ, Dale \\ ML, Ferguson J, Houlton A, Horrocks BR, Clare AS, Fulton DF. \\ Marine antifouling performance of polymer coatings incorporating \\ zwitterions. \\ Biofouling (2017) \\ DOI: https://doi.org/10.1080/08927014.2017.1383983
}

\title{
Copyright:
}

This is an Accepted Manuscript of an article published by Taylor \& Francis in Biofouling on 30/10/2017, available online: $\underline{\text { https://doi.org/10.1080/08927014.2017.1383983 }}$

Date deposited:

$21 / 09 / 2017$

Embargo release date:

30 October 2018

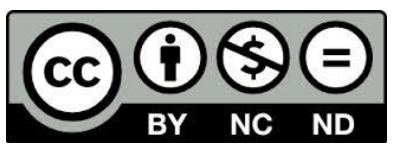

This work is licensed under a

Creative Commons Attribution-NonCommercial-NoDerivatives 4.0 International licence 


\section{Marine antifouling performance of polymer coatings incorporating zwitterions}

\begin{tabular}{|r|l|}
\hline Journal: & Biofouling \\
\hline Manuscript ID & GBIF-2017-0041.R3 \\
\hline Manuscript Type: & Original Paper \\
\hline Keywords: & Zwitterions, polymer coatings, foul-release, Navicula incerta \\
\hline \multicolumn{2}{|l}{} \\
\hline
\end{tabular}

\section{SCHOLARONE $^{\text {m }}$ \\ Manuscripts}


Marine antifouling performance of polymer coatings incorporating zwitterions

Claudia Ventura ${ }^{1}$, Andrew J Guerin ${ }^{2}$, Osama El-Zubir ${ }^{1}$, Antonio J Ruiz-Sanchez ${ }^{1}$, Luke I Dixon ${ }^{1}$, Kevin J

Reynolds $^{3}$, Marie L Dale ${ }^{3}$, James Ferguson ${ }^{3}$, Andrew Houlton ${ }^{1}$, Benjamin R Horrocks ${ }^{1}$, Anthony S Clare ${ }^{2}$,

${ }^{1}$ Chemical Nanoscience Laboratory, School of Chemistry, Newcastle University, Newcastle upon Tyne NE1 7RU, UK

${ }^{2}$ School of Marine Science and Technology, Newcastle University, Newcastle upon Tyne NE1 7RU, UK

${ }^{3}$ International Paint Ltd, Stoneygate Lane, Felling, Gateshead NE10 0JY, UK

- Corresponding author: David A Fulton, Tel: +44 (0)191 208 7065. Email: david.fulton@newcastle.ac.uk 


\begin{abstract}
Zwitterionic materials display antifouling promise, but their potential in marine anti-biofouling is still largely unexplored. This study evaluates the effectiveness of incorporating small quantities (0-20\% on a molar basis) of zwitterions as sulfobetaine methacrylate (SBMA) or carboxybetaine methacrylate (CBMA) into lauryl methacrylate-based coatings whose relatively hydrophobic nature encourages adhesion of the diatom Navicula incerta, a common microfouling organism responsible for the formation of 'slime'. This approach allows potential enhancements in antifouling afforded by zwitterion incorporation to be easily quantified. The results suggest that the incorporation of CBMA does provide a relatively minor enhancement in fouling-release performance, in contrast to SBMA which does not display any enhancement. Studies with coatings incorporating mixtures of varying ratios of the cationic monomer [2-(methacryloyloxy)ethyl]trimethylammonium chloride and the anionic monomer (3-sulfopropyl)methacrylate, which offer a potentially lower cost approach to the incorporation of anionic and cationic charge, suggest these monomers impart little significant effect on biofouling.
\end{abstract}

Keywords: Zwitterions; polymer coatings; foul-release; Navicula incerta

\title{
Introduction
}

Marine biofouling, which can be defined as the accumulation of microorganisms, plants and animals on surfaces immersed in seawater, is an extensive problem for maritime industries. For example, increased hull roughness resulting from biofouling can increase fuel consumption of marine vessels by $40 \%$ at cruising speed, and overall voyage costs by 77\% (Schultz 2007; Schultz et al. 2011, 2015). Biofouling is also a potential problem for aquaculture (Braithwaite \& McEvoy 2004), offshore oil and gas production (Edyvean 1987), underwater sensors (Delauney et al. 2010) and other artificial structures in the marine environment.

Antifouling (AF) coatings are essential for the prevention of biofouling on immersed mobile and stationary structures. The most commonly used AF technologies at present are 'biocidal' coatings. These coatings rely on the controlled release of chemically-active compounds, typically organometals or cuprous oxides, embedded within a polymer matrix binder. The most advanced biocidal AF coatings are based upon a self-polishing strategy, consisting of copolymers that are easily hydrolysable in seawater, resulting in the continuous release of both biocide and binder from the surface of the coating (Chambers et al. 2006). The performance of such coatings is offset by the environmental impact of the continuous release of toxic compounds, leading to the use of tetra-butyltin based coatings being banned (Terlizzi et al. 2001), the prospect of increasing restrictions on copper-based biocides (Dafforn et al. 2011), and regulatory obstacles to the approval of new biocidal compounds. Two alternative strategies to biocidal coatings are non-toxic AF surfaces which rely on surface texture or surface chemistry to deter settlement of fouling organisms, and 'fouling-release' (FR) coatings where settlement and growth of fouling organisms is not necessarily prevented, but the resulting adhesion strength is very low (Lejars et al. 2012). Accumulated biofouling can therefore be released easily by hydrodynamic forces generated by vessel activity or through manual cleaning. However, current commercially-available FR coatings do not prevent the formation of diatom slimes (Holland et al. 2004), are relatively soft and easily damaged, and are effective only when the coated object is in motion above a certain minimum speed (Yebra et al. 2004). 
One promising non-toxic AF approach is based on hydrophilic coatings that prevent adherence of marine organisms. It is well-known that surfaces functionalised with poly(ethylene glycol) (PEG) are resistant to protein adsorption (Zhang et al. 2001; Ma et al. 2004; Krishnan et al. 2008; Ekblad et al. 2008; Leng et al. 2015), and their resistance to the settlement of marine fouling organisms has been demonstrated (Ekblad et al. 2008). However, PEG is readily subject to oxidation, especially in the presence of oxygen and transition-metal ions, and loses its function in biological media (Ostuni et al. 2001; Chen et al. 2005), reducing its utility for a wide range of long-term applications. An alternative emerging class of non-toxic hydrophilic antifouling coatings is based upon zwitterionic polymers. It has been demonstrated that zwitterionic polymers are highly resistant to protein adsorption and cell adhesion (Chen et al. 2005; Zhang et al. 2006; Cheng et al. 2008; Yin et al. 2013) and it is generally believed that water plays an important role in their resistance to fouling. Zwitterionic materials, containing both positive and negative charged units, possess the ability to strongly bind water molecules via electrostatic interactions, forming a hydration layer without disrupting the H-bonding interactions between water molecules (Kitano et al. 2005; Chen et al. 2005; Chen et al. 2010; Schlenoff 2014). Their excellent resistance to protein adsorption and to cell adhesion make zwitterionic coatings promising candidates to deter the formation of the protein film which is considered to represent the first stage in the biofouling process. Since encouraging early laboratory studies (Zhang et al. 2009) with zwitterionic polymer brushes, polymer coatings displaying zwitterions have been prepared and their antibiofouling performance investigated in laboratory-based assays against a selection of organisms. Polyurethanebased coatings incorporating poly(sulfobetaine methacrylate)-containing triblock copolymers showed improved fouling-release performance in laboratory assays with the diatom Navicula incerta and the bacterium Halomonas pacifica (Bodkhe et al. 2014). Polysulfone and polyacrylate-based zwitterionic coatings showed good FR performance against $N$. incerta (Hibbs et al. 2015). Zwitterionic polymer surfaces based on sulfobetaine and carboxybetaine methacrylates also appeared to alter exploration behaviour of cypris larvae of Balanus amphitrite, and ultimately deterred settlement of this barnacle species (Aldred et al. 2010). These encouraging results suggest that zwitterion-containing coatings are worthy of further study.

This study investigates the hypothesis that the incorporation of relatively small quantities of the zwitterionic monomers sulfobetaine methacrylate (SBMA) and carboxybetaine methacrylate (CBMA) (Figure 1) into a coating may improve its AF performance against the diatom $N$. incerta, a common fouling microalga contributing to so-called 'slime layers'. The test coatings were based upon lauryl methacrylate, which is comparatively hydrophobic; diatoms such as $N$. incerta are known to favour more hydrophobic surfaces (Holland et al. 2004), thus making it easier to observe any potential enhancements in anti-biofouling performance afforded by the incorporation of zwitterions. On account of the significant financial costs associated with zwitterionic monomers, it is arguable that a zwitterionic marine anti-biofouling coating would only be commercially viable if its zwitterionic content were relatively low, and thus only coatings containing 0-20\% zwitterion on a molar basis were tested. The effects on fouling by $N$. incerta of systematically altering the balance of positively- and negativelycharged monomers in LMA-based coatings was also investigated by incorporating mixtures of the positively charged monomer [2-(methacryloyloxy)ethyl]trimethylammonium chloride (TMAMA) and the negatively charged monomer 3-sulfopropyl methacrylate (SMA) (Figure 1). These monomers are considerably lower in cost than betaines, and thus could provide a 'pseudo-zwitterionic' nature to coatings in a more cost-effective manner. Tetra(ethylene glycol)-di-methyl methacrylate (TEGDMA) was included as a cross-linker in all coatings to aid 
their stabilities. Atomic force microscopy (AFM) characterisation of the coatings was also performed to determine surface topologies and Young's modulus, two properties which may also influence the degree of fouling.

[Figure 1 here]

\section{Materials and methods}

Absolute EtOH was purchased from Fisher Scientific. All other chemicals were obtained from the Sigma-Aldrich Company (Gillingham, Dorset, UK). Artificial seawater at 32 psu was prepared using Tropic Marin ${ }^{\circledR}$ Sea Water Classic.

\section{Surface preparation}

Prior to use, glass microscope slides (VWR Ltd) were washed with detergent, rinsed with deionised (DI) water, sonicated in DI water for $15 \mathrm{~min}$, sonicated in $\mathrm{EtOH}$ for $15 \mathrm{~min}$, dried with a stream of $\mathrm{N}_{2}$ gas and subjected to oxygen plasma at $70 \mathrm{~W}$ for $15 \mathrm{~min}$ in a plasma asher. Methacryloxypropyltrimethoxysilane-modified glass substrata were prepared by submersion in a solution of $\gamma$-methacryloxypropyltrimethoxysilane (MPS) in EtOH $(0.07 \mathrm{M})$ and covered. After $16 \mathrm{~h}$, the substrata were removed from the bath and dried with a stream of $\mathrm{N}_{2}$ gas. The silane layer was then cured by placing the substrata in an oven at $115^{\circ} \mathrm{C}$ for $30 \mathrm{~min}$. Once cooled, the substrata were sonicated in $\mathrm{EtOH}$ to remove any silane multilayers and then dried with nitrogen. The coatings were prepared by polymerizing them directly onto the functionalized substrata. A sandwich assembly of a clean glass substratum (top) and a functionalized glass substratum (bottom) was assembled, using $0.31 \mathrm{~mm}$ gauge syringe needles as spacers and clips as holders (Figure S1).

\section{Coating preparation}

The mixtures of monomers $(16 \mathrm{mmol})$ in appropriate ratios were dissolved in a mixture of hexyl acetate/methanol $(1: 1,2 \mathrm{ml})$ and stirred for $20 \mathrm{~min}$. TEGDMA $(640 \mu \mathrm{l}, 2.44 \mathrm{mmol})$ and lauryl peroxide (LPO) $(400 \mathrm{mg}, 1 \mathrm{mmol})$ were mixed with the solution and stirred vigorously for $10 \mathrm{~min}$. Then, $144 \mu \mathrm{l}$ of 4- $N, N$-trimethylaniline (TMA) were added to the mixture and stirred for a further $1 \mathrm{~min}$. The monomer formulations were injected into a sandwich of two glass microscope slides (Figure S1) separated by $0.31 \mathrm{~mm}$ gauge needles and the polymer coating was formed after $48 \mathrm{~h}$ at room temperature. The lower of the glass microscope slides was previously silanized (Scheme 1) to display methyl methacrylate functionalities capable of copolymerizing with the formulation in order to covalently bond the coating to the glass substratum. The 'sandwich' was soaked in a salt water bath for 2-4 $\mathrm{d}$ to remove the non-functionalized top glass substratum. The samples were then placed in a salt water bath to leach residual impurities using fresh salt water daily for one week. Coatings were prone to cracking when allowed to dry in air for several days.

\section{Contact angle}

Contact angles (CA, $\theta)$ were measured using a KSV Cam101 at room temperature using the captive bubble method, with air as the light phase and DI water as the heavy phase. All measurements were replicated three times and expressed as a mean, with variance expressed as \pm one standard deviation (SD) from the mean. 


\section{Fourier Transform Infrared Spectroscopy (FTIR)}

FTIR Spectra (in the range of 400 to $4000 \mathrm{~cm}^{-1}$ wavenumbers) were recorded using the ATR accessory of an IRAffinity-1S Fourier transform infrared spectrophotometer at $4 \mathrm{~cm}^{-1}$ spectral resolution. For each spectrum 64 scans were co-added and averaged. The sample was measured as a dry polymer film and the bare ATR accessory was used as a background. Spectral references (sulfobetaine) were obtained from the AIST Spectral Database for Organic Compounds (http://sdbs.db.aist.go.jp/sdbs/cgi-bin/cre_index.cgi).

\section{Atomic force microscopy (AFM)}

A Digital Instruments Multimode-8 with Nanoscope V controller and E scanners (Bruker, Germany) was used for acquiring AFM images and force curves. Nanoscope software version 9.1 was used to control the microscope. The AFM data were processed with NanoScope Analysis 1.50 software (Bruker). All experiments were performed in an AFM fluid cell and under artificial seawater to investigate surface topology, adhesion and Young's modulus of the test coatings. Silicon tips on V-shaped $\mathrm{Si}_{3} \mathrm{~N}_{4}$ cantilevers (model DNP, Bruker) were used for imaging and force measurement. The AFM probes were cleaned by exposure to oxygen plasma at $70 \mathrm{~W}$ for $10 \mathrm{~min}$. For morphology and roughness measurements, ScanAsyst mode in fluid with low load force (of the order of picoNewtons) was used to minimise deformation or damage to the samples. Roughness was measured on a sample area of $100 \mu \mathrm{m}^{2}$. The root mean square of roughness $\left(\mathrm{R}_{\mathrm{q}}\right)$ was calculated from five randomly selected areas of each coating. Force Volume-Contact mode was employed to obtain force curves that were used to assess Young's modulus and adhesion force. For both Young's modulus and adhesion forces, the deflection sensitivity of each cantilever was calibrated by performing closed-loop $\mathrm{Z}$ force curves on a flat array of silicon. A titanium sample with very sharp grain features (RS-12M, Bruker, Germany) was used to measure the radius of curvature of the AFM probes. The spring constant of each cantilever was calibrated using the thermal tune method (Ohler 2007).

\section{Diatom adhesion / ease-of-removal assay}

Samples were fully equilibrated in artificial seawater (30 psu) prior to testing. Cells of the laboratory-cultured diatom, $N$. incerta, were resuspended in $0.22 \mu \mathrm{m}$ filtered artificial seawater (Tropic Marin, $30 \mathrm{psu}$ ). As a reference surface, polydimethyl siloxane (PDMS; clear Dow Corning 3-0213) was cast onto glass slides were produced and pre-leached in filtered de-ionised water for 28 days, and transferred to artificial seawater ( $30 \mathrm{psu})$ for $24 \mathrm{~h}$ prior to testing. Five replicate slides of each surface were placed in quadriPERM dishes (Greiner) and $10 \mathrm{ml}$ of diatom suspension were added to each slide well. Slides were left in natural light at room temperature for $2 \mathrm{~h}$ to settle, and then gently washed in artificial seawater to remove unattached cells. Two replicates of each surface were exposed to a shear stress of 25.76 Pathe in a flow cell for $5 \mathrm{~min}$ (Schultz et al. 2000). Slides were examined using fluorescence microscopy, with illumination at $546 \mathrm{~nm}$ (excitation) / $590 \mathrm{~nm}$ (emission). For each replicate slide, the density of diatom cells was measured as the average of 12 manual counts of cells per field of view. The percentage removal of diatom cells following shear exposure was calculated for each replicate slide compared to the mean density of diatom cells on slides not exposed to shear. Diatom densities with and without shear exposure, and the percentage removal of cells following flow exposure, were compared among surfaces using ANOVA, with Welch's correction where variances were unequal. 
Biofilm growth / removal test

Biofilms were developed on the SBMA- and CBMA-based coatings at a 'slime farm' facility. This consisted of a $120 \times 165 \times 30 \mathrm{~cm}$ flow-through seawater tank fed with sand-filtered natural seawater maintained at $19.5 \pm 1^{\circ} \mathrm{C}, 35$ $\pm 1 \mathrm{psu}$, and pH 7.8. Samples, along with slides coated with grey-pigmented $\mathrm{PDMS}\left(\mathrm{Fe}_{2} \mathrm{O}_{3}\right.$ and $\mathrm{TiO}_{2}$ pigments $)$ were placed in quadriPERM dishes at the bottom of the tank for seven weeks to allow biofilm development. Slides were photographed after 2, 4 and 7 weeks. After 7 weeks, samples were tested for biofilm release. Biofilmed slides were mounted in a flow cell and fully turbulent flow was passed across the surfaces. Flow speed was increased step-wise from zero to $2.4 \mathrm{~ms}^{-1}$, with speed kept constant for $60 \mathrm{~s}$ at each speed (speed increments were 1.4, 1.7, 2.0, $2.4 \mathrm{~ms}^{-1}$ ). Slides were photographed before each speed increase, recording the speed at which all visible biofilm was removed.

\section{Results and discussion Synthesis of zwitterionic coatings}

A simple route was developed for preparing zwitterionic and pseudo-zwitterionic hydrogel coatings (C1-C12) on standard glass microscope slides. Mixtures of monomer formulations (Table 1), which utilize a redox initiator system LPO/TMA, were injected into a sandwich of two glass microscope slides separated by $0.31 \mathrm{~mm}$ gauge needles and the polymer coating was obtained after $48 \mathrm{~h}$. The lower of the glass microscope slides was silanized (Figure 2) to display methyl methacrylate functionalities capable of copolymerizing with the formulation in order to covalently bond the coating to the glass substratum. After polymerization, the sandwich system was soaked in artificial seawater for 2-3 d in order to remove the top glass, and the coatings were then immersed in fresh artificial seawater for one week to leach unreacted monomers. After leaching coating thickness was found to be in the range $\sim 0.1-0.3 \mathrm{~mm}$.

[Figure 2 here]

\section{Physico-chemical characterisation}

To verify that the composition of the polymer coatings reflected monomer and cross-linker feed ratios, elemental analysis of each coating was performed. In all cases the measured elemental compositions matched within experimental error the expected compositions (Table S1 in Supporting information), suggesting that all monomers and crosslinkers were successfully incorporated into the coatings. To further confirm the coating compositions, FTIR analysis of the coatings was performed. The FTIR spectra of zwitterionic coatings comprising LMA and SBMA (C1-C4) were dominated by the LMA signals although diagnostic sulfonate-related bands were visible near $1040 \mathrm{~cm}^{-1}$ (Figure S2 in Supporting information). The 10\% SBMA (C3) and 20\% SBMA (C4) samples were distinguishable by FTIR using this band, and integration of the spectra across the band affords ratios of $1.8: 1$, in satisfactory agreement with the expected 20:10 monomer ratios based upon monomer compositions. It was not possible to distinguish the $1 \%$ SBMA containing sample (C2) from pure poly(LMA) (C1) because of the overlap of S-O stretching modes with other dominant C-H bending/deformation and C-N modes in the $1100-1500 \mathrm{~cm}^{-1}$ region. For the pseudo zwitterionic coatings C8-C10 it was possible to use the sulfonate-related bands visible near 1060 $\mathrm{cm}^{-1}$ to verify the content of SMA (Figure S3 in Supporting information). It was not possible to use either FTIR or 
Raman spectroscopy to characterize the coatings containing CBMA (C5-C7) as diagnostic signals were too similar to distinguish even at 20\% CBMA. FTIR spectra of coatings comprising LMA (90\%) and SMA and TMAMA comonomers (10\%) were dominated by the signals for LMA, but sulfonate-related bands are visible near $1060 \mathrm{~cm}^{-1}$ (Figure S3 in Supporting information, black rectangle). Integration of this band allows the relative compositions of the coatings containing 10\% SMA (C8), 7.5\% SMA (C9) and 5\% SMA (C10) to be confirmed. Coatings containing smaller fractions of SMA gave spectra that were difficult to distinguish from LMA. Taken together, the results of elemental analysis and FTIR studies indicate that the compositions of the polymer coatings reflects their monomer and crosslinker feed ratios on a relative basis.

The polymer coatings were characterized by measuring the contact angles (Table 1; Figure 3). The coating containing $0 \%$ zwitterion $(\mathrm{C} 1)$ had the highest contact angle $43 \pm 3^{\circ}$, indicating it possessed the lowest hydrophilicity. Contact angles decreased as the content of zwitterionic monomer increased and similar values were observed between the SBMA and CBMA series (Figure 3a). This observation indicates that coating hydrophilicity increased as zwitterion incorporation increased, and suggests that zwitterionic monomers were displayed upon the surfaces. For coatings $\mathrm{C} 8-\mathrm{C} 12$, contact angle increased with the content of positively charged monomer (Figure $3 b$ ), indicating a concurrent decrease in coating hydrophilicity. Contact angles obtained for these coatings were largely in agreement with other hydrogel-like coatings reported in the literature (Magin et al. 2011; Yin et al. 2013; Paradiso et al. 2014). The water content and swelling ratios (Q) of coatings were also determined (Table S1 in Supporting information).

[Table 1 here]

[Figure 3 here]

AFM topographical imaging of all coatings was performed on a sample area of $100 \mu \mathrm{m}^{2}$ to provide information on surface topology (Figure 4, Table 2). Coating C1 (0\% zwitterion) was relatively flat and featureless (Figure 4a) with a root mean square of roughness $\left(\mathrm{R}_{\mathrm{q}}\right)$ of $11 \mathrm{~nm}$ (Table 2). Coating C2 (1\% SBMA) displayed (Figure $\left.4 \mathrm{~b}\right)$ irregular and micron-sized dimple-like features within an otherwise relatively flat surface. Coating $\mathrm{C} 3$ (10\% SBMA) displayed a higher density of smaller dimple-like features (Figure 4c), whereas coating C4 (20\% SBMA) appeared to have lost the dimple-like effects, instead presenting an uneven surface topology (Figure 4d). These observations suggest that incorporating increasing amounts of SBMA into the LMA-based coating led to considerable increases in surface roughness with significant and unpredicted differences in surface topologies. The reasons for this change in topology are currently unclear but most likely arise because of a degree of phase separation when SBMA monomers are formulated into the hydrophobic LMA-based coating. The incorporation of CBMA into the LMA-based coating, on the other hand, did not lead to the formation of any significant surface features (Figure 4e-g), with only small increases in surface roughness observed as increasing quantities of CBMA were incorporated (Table 2). These observations suggest that incorporating CBMA into the LMA-based coating resulted in less disruption to the surface topology than the addition of SBMA. For the coatings (C8-C12), AFM analysis revealed relatively flat and featureless surfaces throughout the series (Figure 4h-1), and the measured surface roughness was found to be within a relatively narrow range of $\sim 12-44 \mathrm{~nm}$ (Table 2). These observations 
suggest that incorporating TMAMA and/or SMA into the LMA-based coating also did not have a substantial effect on surface topology or roughness. AFM nano-indentation experiments were also performed to determine Young's modulus, which provides a measurement of coating stiffness. This experiment also allowed determination of adhesion, a measurement of the adherence between the AFM probe and the surface. Addition of CBMA resulted in a large increase in Young's modulus, with greater proportions of CBMA giving higher values (Figure 5a, Table 2). A decrease was observed when 1\% SBMA was incorporated (C2; Figure 5a, Table 2), but addition of greater proportions of SBMA appeared to lead to a modest increase in Young's modulus (C3-C4). The results suggest that SBMA-containing coatings are, in general, more stiff and rougher than their CBMA-containing or mixed-charge counterparts. The Young's moduli of coatings (C8-C12) are shown in Figure $5 \mathrm{~b}$ and Table 2, where it can be seen that the minimum value is obtained when the charged monomers are present in near equimolar ratios. Those coatings possessing excess positively- or negatively-charged monomer compositions display larger values of Young's modulus.

[Table 2 here]

[Figure 4 here]

Surface adhesion decreased as SBMA or CBMA were formulated into the coatings (Figure 5c, Table 2). For the series C8-C12 (Figure 5d, Table 2), adhesion was fairly constant within the range 0.20-0.38 nN. These observations suggest that the introduction of zwitterionic monomers reduced adhesion strength between the AFM tip and the surface. Taken together, these AFM studies highlight that the incorporation of small amounts of zwitterion into LMA-based coatings can have significant effects upon the resulting topology and mechanical properties, even at only $1 \%$ zwitterion.

[Figure 5 here]

\section{Diatom adhesion / ease-of-release}

The AF behaviour of the coatings was assessed in the laboratory against the diatom $N$. incerta. Compared to pure LMA, coatings containing SBMA (C2-C4) had similar densities of adhered diatom cells prior to exposure to shear stress (Welch's ANOVA; $\mathrm{F}=1.21, \mathrm{df}=3, p=0.41$ ). However, diatom density after shear exposure did differ among coatings with different levels of SBMA (ANOVA; $\mathrm{F}=7.35, \mathrm{df}=3, p=0.042$ ); the density of cells was greatest on the surface with the highest proportion of SBMA (C4; Figure 6a). Incorporation of SBMA into LMA also had a significant effect on percent removal of cells (ANOVA; $\mathrm{F}=7.0236$, $\mathrm{df}=3, p=0.045$ ), with lowest proportional removal from the surface with most SBMA (C4; Figure 6b). These data suggest that incorporation of increasing amounts of SBMA decreased AF performance relative to pure LMA.

There was no significant variation in the diatom cell density among the CBMA series (C5-C7) prior to exposure to shear (Welch's ANOVA, $\mathrm{F}=0.7526, \mathrm{df}=3, p=0.58$ ). Inclusion of increasing amounts of CBMA had an effect on both final cell density (ANOVA; $\mathrm{F}=10.87, \mathrm{df}=3, p=0.022$ ) and percentage removal (ANOVA, $\mathrm{F}=$ 9.046, $\mathrm{df}=3, p=0.030$ ) of $N$. incerta cells. In contrast to SBMA, CBMA improved the performance of LMA, with the $20 \%$ CBMA (C7) surface having the lowest final cell density (Figure 6c) and the highest percent removal 
(Figure 6d). These data suggest that, in contrast to SBMA, incorporation of CBMA did improve the AF performance of the underlying LMA coating. This differs from the results of other studies, which have found that pure SBMA self-assembled-monolayers (SAMs) performed better than similar CBMA surfaces in AF assays using the same diatom species (Finlay et al. 2013; Bauer et al. 2016).

It may seem surprising that the zwitterionic surfaces did not perform better than PDMS, since previous studies of zwitterionic surfaces generally suggest superior performance against diatoms (Bodkhe et al. 2014; Hibbs et al. 2015). The reason for this discrepancy is likely to result from the underlying properties of the LMA surface; the AF performance of $100 \%$ LMA is similar, or inferior, to PDMS (Figure 6; LMA is coating C1). The addition of the zwitterionic material to the LMA coatings, at the levels tested here, appears to have had only a small impact on the AF performance of LMA.

Varying the proportion of two oppositely charged monomers (C8-C12) had no significant effect on the initial densities of adhered diatom cells (ANOVA; $\mathrm{F}=0.357, \mathrm{df}=4, p=0.833$ ), the density of cells after exposure to shear stress (ANOVA; $\mathrm{F}=1.025, \mathrm{df}=4, p=0.465$ ), or the percentage of cells removed following exposure to shear stress (ANOVA; $\mathrm{F}=0.949, \mathrm{df}=4, p=0.497$ ). Though all differences among test surfaces were nonsignificant, it did appear (Figure 6e,f) that the worst performing surface (highest final density, lowest percentage removal) was the surface with equal amounts of the two charged monomers (C10). None of the surfaces performed better than unmodified LMA (C1). It is worthwhile noting that there does not appear to be any correlation between the water content and swelling ratios $(\mathrm{Q})$ of coatings and their AF performance.

[Figure 6 here]

\section{Biofilm growth / removal test}

The test surfaces showed very low fouling even after seven weeks immersion in the 'slime farm' tank, with all the LMA-based surfaces appearing to show less fouling than the PDMS standards (Figure 7). Coatings C3 and C5-C7 underwent biofilm removal testing in the flow cell; the remaining coatings only showed a low amount of weakly adhered biofouling that was removed during transportation. At a flow speed of $1.7 \mathrm{~ms}^{-1}$ all visible biofilm was removed from C5 and C7 (Figure S4-S6 in Supporting information), while full removal from C3 and C6 required the slightly higher flow speed of $2.0 \mathrm{~ms}^{-1}$. The PDMS standards were still visibly biofilmed after exposure to the maximum flow speed of $2.4 \mathrm{~ms}^{-1}$ (Figure S8 in Supporting information). These results indicate generally good AF and FE performance against the biofilms formed in the 'slime farm'. In contrast to the diatom removal assay results, they also show a markedly better performance than the PDMS standards. However, there was little detectable variation among different levels of the two different zwitterions.

[Figure 7 here]

\section{Effectiveness of SBMA and CBMA as additives to the LMA polymer surface}

The differences observed in AF performance against $N$. incerta between the coatings containing SBMA and those containing CBMA may arise from differences in how the monomers interact with water, differences in surface properties, or combinations of these two factors. Regarding their interactions with water, carboxybetaines have http://mc.manuscriptcentral.com/gbif 
cationic and anionic groups that are quite different in charge densities, leading to fewer associations between monomers (Shao et al. 2014) and consequently moieties in carboxybetaine materials are very hydrated. This feature is important, as the fouling resistance properties of zwitterionic materials may arise from the formation of a strong hydration layer without disturbing the H-bonding interactions between water molecules (Kitano et al. 2005; Chen et al. 2005; Chen et al. 2010; Schlenoff 2014). Sulfobetaines possess more similar charge densities, and being less well hydrated might be less effective in anti-biofouling. Regarding possible differences in surface properties, the incorporation of SBMA did reduce the adhesion between the AFM tip and the coatings. However, any beneficial effect of the presence of SBMA on surface chemistry may have been masked by the effect of SBMA on coating roughness. Roughness at various scales has a strong influence on AF performance (Schumacher et al. 2007; Scardino et al. 2009) and it is possible that the lower performance of the SBMA-containing coatings was driven by the uncontrolled and substantial increases in surface roughness in the coatings. Inclusion of CBMA, on the other hand, did not affect surface roughness to the same degree, although it did lead to increased Young's modulus and reduced AFM tip adhesion compared to both unmodified LMA and the SBMA-modified coatings. These differences in the effects of the two zwitterions on surface properties would appear to explain why the results are different from similar experiments conducted using pure zwitterionic SAMs (Finlay et al. 2013; Bauer et al. 2016). The results of the biofilm assay do not appear to differentiate between coatings with SBMA and CBMA, and show generally good performance on all LMA-based coatings. It is possible that this test was less sensitive to differences among these particular coatings.

The coatings C8-C12 did not vary significantly in performance, which is in agreement with some of the physical characterisation data; contact angle, roughness, and AFM tip adhesion did not vary substantially among these coatings. There did appear to be a (non-significant) tendency for the surfaces with a net excess of positivelyor negatively-charged monomers to perform better than the surfaces with a more balanced ratio of negative and positive charges. This behaviour was not anticipated since it has been reported that coatings formed by mixed positively and negatively charged self-assembled monolayers (SAMs) or hydrogel of equal valence are highly resistant to protein adsorption (Holmlin et al. 2001; Chen et al. 2006; Chen \& Jiang 2008). Young's modulus varied substantially among the coatings $\mathrm{C} 8-\mathrm{C} 12$, and this appeared to reflect differences in coating performance - the worst performing coating $(\mathrm{C} 10)$ was the one with the lowest Young's modulus, while the coatings with the highest Young's modulus (C8 and C12), performed best.

\section{Conclusions}

Polymer surfaces incorporating relatively low amounts of zwitterion have been prepared, characterized and their performance assessed in the laboratory against $N$. incerta. These results suggest that incorporation of SBMA into LMA-based coatings did not enhance the FR properties, possibly on account of the nature of the monomer and/or changes in surface roughness, but that the incorporation of CBMA did lead to an improvement. Coatings containing a mixture of positively and negatively charged monomers performed best when there was a net excess of either positively- or negatively-charged monomers, rather than when there was equimolar amounts of positivelyand negatively-charged monomers. All coatings performed well in controlled-field studies where they were immersed in filtered seawater for several weeks, with all fouling being removed easily with relatively low hydrodynamic shear. The results suggest that the incorporation of relatively small amounts of zwitterions into 
polymer coatings may lead to enhancements in FR properties, although much work will have to be done to identify optimal formulations, with particular attention paid to the possible effects of surface roughness and topology.

\section{Funding}

This study received funding from the European Community's Seventh Framework program FP7/KBBE [grant number 614034] (SEAFRONT).

\section{References}

Aldred N, Li G, Gao Y, Clare AS, Jiang S. 2010. Modulation of barnacle (Balanus amphitrite Darwin) cyprid settlement behavior by sulfobetaine and carboxybetaine methacrylate polymer coatings. Biofouling. 26:673-83. doi:10.1080/08927014.2010.506677.

Bauer S, Finlay JA, Thomé I, Nolte K, Franco SC, Ralston E, Swain GE, Clare AS, Rosenhahn A. 2016. Attachment of algal cells to zwitterionic self-assembled monolayers comprised of different anionic compounds. Langmuir. 32:5663-5671. doi:10.1021/acs.langmuir.6b00839.

Bodkhe RB, Stafslien SJ, Daniels J, Cilz N, Muelhberg AJ, Thompson SEM, Callow ME, Callow JA, Webster DC. 2014. Zwitterionic siloxane-polyurethane fouling-release coatings. Prog Org Coatings. 78:369-380. doi:10.1016/j.porgcoat.2014.07.011.

Braithwaite RA, McEvoy LA. 2004. Marine biofouling on fish farms and its remediation. Adv Mar Biol. 47:215252.

Chambers LD, Stokes KR, Walsh FC, Wood RJK. 2006. Modern approaches to marine antifouling coatings. Surf Coatings Technol. 201:3642-3652. doi:10.1016/j.surfcoat.2006.08.129.

Chen S, Jiang S. 2008. A new avenue to nonfouling materials. Adv Mater. 20:335-338. doi:10.1002/adma.200701164.

Chen S, Li L, Zhao C, Zheng J. 2010. Surface hydration: principles and applications toward low-fouling/nonfouling biomaterials. Polymer (Guildf). 51:5283-5293. doi:10.1016/j.polymer.2010.08.022.

Chen S, Yu F, Yu Q, He Y, Jiang S. 2006. Strong resistance of a thin crystalline layer of balanced charged groups to protein adsorption. Langmuir. 22:8186-8191. doi:10.1021/la061012m.

Chen S, Zheng J, Li L, Jiang S. 2005. Strong resistance of phosphorylcholine self-assembled monolayers to protein adsorption: insights into nonfouling properties of zwitterionic materials. J Am Chem Soc. 127:14473-8. doi:10.1021/ja054169u.

Cheng G, Xue H, Zhang Z, Chen S, Jiang S. 2008. A switchable biocompatible polymer surface with selfsterilizing and nonfouling capabilities. Angew Chemie - Int Ed. 47:8831-8834. doi:10.1002/anie.200803570.

Dafforn KA, Lewis JA, Johnston EL. 2011. Antifouling strategies: history and regulation, ecological impacts and mitigation. Mar Pollut Bull. 62:453-465. doi:10.1016/j.marpolbul.2011.01.012. 
Delauney L, Compère C, Lehaitre M. 2010. Biofouling protection for marine environmental sensors. Ocean Sci. 6:503-511. doi:10.5194/os-6-503-2010.

Edyvean RGJ. 1987. Biodeterioration problems of North Sea oil and gas production-a review. Int Biodeterior. 23:199-231. doi:10.1016/0265-3036(87)90002-9.

Ekblad T, Bergström G, Ederth T, Conlan SL, Mutton R, Clare AS, Wang S, Liu Y, Zhao Q, D’Souza F, et al. 2008. Poly(ethylene glycol)-containing hydrogel surfaces for antifouling applications in marine and freshwater environments. Biomacromolecules. 9:2775-83. doi:10.1021/bm800547m.

Finlay JA, Schultz MP, Cone G, Callow ME, Callow JA. 2013. A novel biofilm channel for evaluating the adhesion of diatoms to non-biocidal coatings. Biofouling. 29:401-11. doi:10.1080/08927014.2013.777046.

Hibbs MR, Hernandez-Sanchez BA, Daniels J, Stafslien SJ. 2015. Polysulfone and polyacrylate-based zwitterionic coatings for the prevention and easy removal of marine biofouling. Biofouling. 31:613-624. doi:10.1080/08927014.2015.1081179.

Holland R, Dugdale TM, Wetherbee R, Brennan AB, Finlay JA, Callow JA, Callow ME. 2004. Adhesion and motility of fouling diatoms on a silicone elastomer. Biofouling. 20:323-9. doi:10.1080/08927010400029031.

Holmlin RE, Chen X, Chapman RG, Takayama S, Whitesides GM. 2001. Zwitterionic SAMs that resist nonspecific adsorption of protein from aqueous buffer. Langmuir. 17:2841-2850. doi:10.1021/1a0015258.

Kitano H, Tada S, Mori T, Takaha K, Gemmei-Ide M, Tanaka M, Fukuda M, Yokoyama Y. 2005. Correlation between the structure of water in the vicinity of carboxybetaine polymers and their blood-compatibility. Langmuir. 21:11932-11940. doi:10.1021/la0515571.

Krishnan S, Weinman CJ, Ober CK. 2008. Advances in polymers for anti-biofouling surfaces. J Mater Chem. 18:3405. doi:10.1039/b801491d.

Lejars M, Margaillan A, Bressy C. 2012. Fouling release coatings: a nontoxic alternative to biocidal antifouling coatings. Chem Rev. 112:4347-90. doi:10.1021/cr200350v.

Leng C, Hung HC, Sun S, Wang D, Li Y, Jiang S, Chen Z. 2015. Probing the surface hydration of nonfouling zwitterionic and PEG materials in contact with proteins. ACS Appl Mater Interfaces. 7:16881-16888. doi:10.1021/acsami.5b05627.

Ma H, Hyun J, Stiller P, Chilkoti A. 2004. "Non-fouling” oligo(ethylene glycol)-functionalized polymer brushes synthesized by surface-initiated atom transfer radical polymerization. Adv Mater. 16:338-341. doi:10.1002/adma.200305830.

Magin CM, Finlay JA, Clay G, Callow ME, Callow JA, Brennan AB. 2011. Antifouling performance of crosslinked hydrogels: refinement of an attachment model. Biomacromolecules. 12:915-22. 
doi:10.1021/bm101229v.

Ohler B. 2007. Cantilever spring constant calibration using laser Doppler vibrometry. Rev Sci Instrum. 78:63701. doi:10.1063/1.2743272.

Ostuni E, Chapman RG, Holmlin RE, Takayama S, Whitesides GM. 2001. A survey of structure-property relationships of surfaces that resist the adsorption of protein. Langmuir. 17:5605-5620. doi:10.1021/la010384m.

Paradiso P, Galante R, Santos L, Alves De Matos AP, Colaço R, Serro AP, Saramago B. 2014. Comparison of two hydrogel formulations for drug release in ophthalmic lenses. J Biomed Mater Res - Part B Appl Biomater. 102B:1170-1180. doi:10.1002/jbm.b.33099.

Scardino AJ, Hudleston D, Peng Z, Paul NA, de Nys R. 2009. Biomimetic characterisation of key surface parameters for the development of fouling resistant materials. Biofouling. 25:83-93. doi:10.1080/08927010802538480.

Schlenoff JB. 2014. Zwitteration: Coating surfaces with zwitterionic functionality to reduce nonspecific adsorption. Langmuir. 30:9625-9636. doi:10.1021/la500057j.

Schultz MP. 2007. Effects of coating roughness and biofouling on ship resistance and powering. Biofouling. 23:331-41. doi:10.1080/08927010701461974.

Schultz MP, Bendick JA, Holm ER, Hertel WM. 2011. Economic impact of biofouling on a naval surface ship. Biofouling. 27:87-98. doi:10.1080/08927014.2010.542809.

Schultz MP, Finlay JA, Callow ME, Callow JA. 2000. A turbulent channel flow apparatus for the determination of the adhesion strength of microfouling organisms. Biofouling. 15:243-251. doi:10.1080/08927010009386315.

Schultz MP, Walker JM, Steppe CN, Flack KA. 2015. Impact of diatomaceous biofilms on the frictional drag of fouling-release coatings. Biofouling. 31:759-773. doi:10.1080/08927014.2015.1108407.

Schumacher JF, Carman ML, Estes TG, Feinberg AW, Wilson LH, Callow ME, Callow JA, Finlay JA, Brennan AB. 2007. Engineered antifouling microtopographies - effect of feature size, geometry, and roughness on settlement of zoospores of the green alga Ulva. Biofouling. 23:55-62. doi:10.1080/08927010601136957.

Shao Q, Mi L, Han X, Bai T, Liu S, Li Y, Jiang S. 2014. Differences in cationic and anionic charge densities dictate zwitterionic associations and stimuli responses. J Phys Chem B. 118:6956-6962. doi:10.1021/jp503473u.

Terlizzi A, Fraschetti S, Gianguzza P, Faimali M, Boero F. 2001. Environmental impact of antifouling technologies: state of the art and perspectives. Aquat Conserv Mar Freshw Ecosyst. 11:311-317. doi:10.1002/aqc. 459 .

Yebra DM, Kiil S, Dam-Johansen K. 2004. Antifouling technology—past, present and future steps towards 
efficient and environmentally friendly antifouling coatings. Prog Org Coatings. 50:75-104. doi:10.1016/j.porgcoat.2003.06.001.

Yin H, Akasaki T, Lin Sun T, Nakajima T, Kurokawa T, Nonoyama T, Taira T, Saruwatari Y, Gong JP. 2013. Double network hydrogels from polyzwitterions: high mechanical strength and excellent anti-biofouling properties. J Mater Chem B. 1:3685-3693. doi:10.1039/C3TB20324G.

Zhang F, Kang ET, Neoh KG, Wang P, Tan KL. 2001. Modification of Si(100) surface by the grafting of poly(ethylene glycol) for reduction in protein adsorption and platelet adhesion. J Biomed Mater Res. 56:324-332. doi:10.1002/1097-4636(20010905)56:3<324::AID-JBM1100>3.0.CO;2-P.

Zhang Z, Chao T, Chen S, Jiang S. 2006. Superlow fouling sulfobetaine and carboxybetaine polymers on glass slides. Langmuir. 22:10072-10077. doi:10.1021/la062175d.

Zhang Z, Finlay JA, Wang L, Gao Y, Callow JA, Callow ME, Jiang S. 2009. Polysulfobetaine-grafted surfaces as environmentally benign ultralow fouling marine coatings. Langmuir. 25:13516-21. doi:10.1021/la901957k. 


\section{Captions to Figures}

Figure 1. Chemical structures of the monomers and cross-linker used for the preparation of the coatings.

Figure 2. Preparation of polymer coatings on glass substrata using LMA, TEGDMA and the zwitterionic monomers SBMA or CBMA, or a combination of the positively and negatively charged monomers SMA and TMAMA. Reaction conditions: (a) EtOH, room temperature, 16 h; (b) LPO/TMA, MeOH/hexyl acetate, room temperature, $48 \mathrm{~h}$.

\section{<<Editor: "glass substrate" should read "Glass substratum" and "Initiator" should read "initiator"〉>}

Figure 3. (a) Relationship between contact angles $\left(^{\circ}\right)$ and the percent content of the zwitterionic monomers SBMA (white symbols, surfaces $\mathrm{C} 2-\mathrm{C} 4$ ) and CBMA (black circles, surfaces C5-C7). The black square is pure LMA (C1). (b) Relationship between contact angles $\left({ }^{\circ}\right)$ and the percent content of TMAMA in coatings C8-C12. Error bars are \pm 1 SD.

Figure 4. Representative AFM topographical images of (a) the LMA coating (C1), (b-d) SBMA-containing coatings (C2-C4), (e-g) CBMA-containing coatings (C5-C7), and (h-c) the mixed-monomer coatings (C8-C12).

$<<$ Editor: "'net', (x2) should read 'Net'">>

Figure 5.(a) Young's modulus of LMA coating C1 (black) and as a function of SBMA content (light grey) and CBMA content (dark grey). (b) Young's modulus as a function of TMAMA content in surfaces C8-C12. (c) Adhesion strength of AFM tip to LMA coating C1 (black) and as a function of SBMA content (light grey) and CBMA content (dark grey). (d) Adhesion strength of AFM tip as a function of TMAMA content in surfaces C8C12. Error bars are $+1 \mathrm{SD}$.

Figure 6. Performance of test coatings in adhesion and ease-of-removal assay using $N$. incerta. Dark grey bars show density of cells with no exposure to shear; white bars show density after exposure to a shear stress of 25.76 Pa for 5 min $(a, c, e)$. Light grey bars show the percent removal of cells resulting from exposure to shear (b,d,f). $(a, b)$ SBMA series: C1 - $100 \%$ LMA; C2 - LMA with $1 \%$ SBMA; C3 - LMA with $10 \%$ SBMA; C4; LMA with $20 \%$ SBMA. c,d) CBMA series: C1 - $100 \%$ LMA; C5 - LMA with $1 \%$ CBMA; C6 - LMA with 10\% CBMA; C7 LMA with 20\% CBMA. (e,f) Mixed monomer surface series (for detailed composition data see Table 1); no data were obtained for surface C11. Error bars are +1 SD.

Figure 7. Coatings C1-C7 and PDMS standards after seawater immersion in the 'slime farm' for 2 weeks (left) and 7 weeks (right). Slides had not been exposed to shear.

\section{Captions to Tables}

Table 1. Summary of the zwitterionic polymer coatings prepared.

Table 2. Root mean square of roughness (Rq), Young's modulus and the adhesion force of the polymer coatings. 


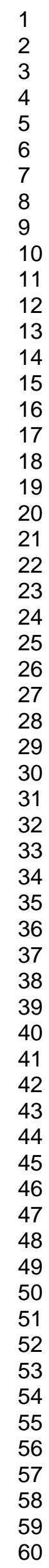

http://mc.manuscriptcentral.com/gbif 
Table 1. Summary of the zwitterionic polymer coatings prepared

\begin{tabular}{|c|c|c|c|c|c|c|}
\hline Coating & $\begin{array}{c}\text { Content of } \\
\text { SBMA }(\%)^{(a)}\end{array}$ & $\begin{array}{c}\text { Content of } \\
\text { CBMA }(\%)^{(a)}\end{array}$ & $\begin{array}{l}\text { Content of } \\
\text { SMA }(\%){ }^{(a)}\end{array}$ & $\begin{array}{c}\text { Content of } \\
\text { TMAMA }(\%){ }^{(a)}\end{array}$ & $\begin{array}{c}\text { Content of } \\
\text { LMA (\%) }{ }^{(a)}\end{array}$ & $\begin{array}{c}\text { Air in water } \\
\text { contact angle }\left({ }^{\circ}\right)\end{array}$ \\
\hline C1 & 0 & 0 & - & - & 100 & $43 \pm 3$ \\
\hline C2 & 1 & - & - & - & 99 & $41 \pm 2$ \\
\hline C3 & 10 & - & - & - & 90 & $37 \pm 6$ \\
\hline C4 & 20 & - & - & - & 80 & $28 \pm 3$ \\
\hline C5 & - & 1 & - & - & 99 & $42 \pm 5$ \\
\hline C6 & - & 10 & - & - & 90 & $34 \pm 4$ \\
\hline C7 & - & 20 & - & - & 80 & $27 \pm 5$ \\
\hline C8 & - & - & 10 & 0 & 90 & $32 \pm 3$ \\
\hline C9 & - & - & 7.5 & 2.5 & 90 & $36 \pm 4$ \\
\hline C10 & - & - & 5 & 5 & 90 & $39 \pm 3$ \\
\hline C11 & - & - & 2.5 & 7.5 & 90 & $40 \pm 1$ \\
\hline C12 & - & - & 0 & 10 & 90 & $52 \pm 1$ \\
\hline
\end{tabular}

(a) Percentage composition on a molar basis. 
Table 2. Root mean square of roughness (Rq), Young's modulus and the adhesion force of the polymer coatings.

\begin{tabular}{cccc}
\hline Coating & Roughness / nm & $\begin{array}{c}\text { Young's modulus / } \\
\text { MPa }\end{array}$ & Adhesion / nN \\
\hline C1 & 10.76 & 4.83 & 2.43 \\
C2 & 153.80 & 0.98 & 2.26 \\
C3 & 159.20 & 4.94 & 0.95 \\
C4 & 105.74 & 20.03 & 1.15 \\
C5 & 11.09 & 82.22 & 0.56 \\
C6 & 19.18 & 96.16 & 0.22 \\
C7 & 24.88 & 109.65 & 0.06 \\
C8 & 11.87 & 150.30 & 0.22 \\
C9 & 21.56 & 59.33 & 0.20 \\
C10 & 14.04 & 15.89 & 0.31 \\
C11 & 28.66 & 116.50 & 0.38 \\
C12 & 44.10 & 132.38 & 0.19 \\
\hline
\end{tabular}


Page 19 of 33

Biofouling
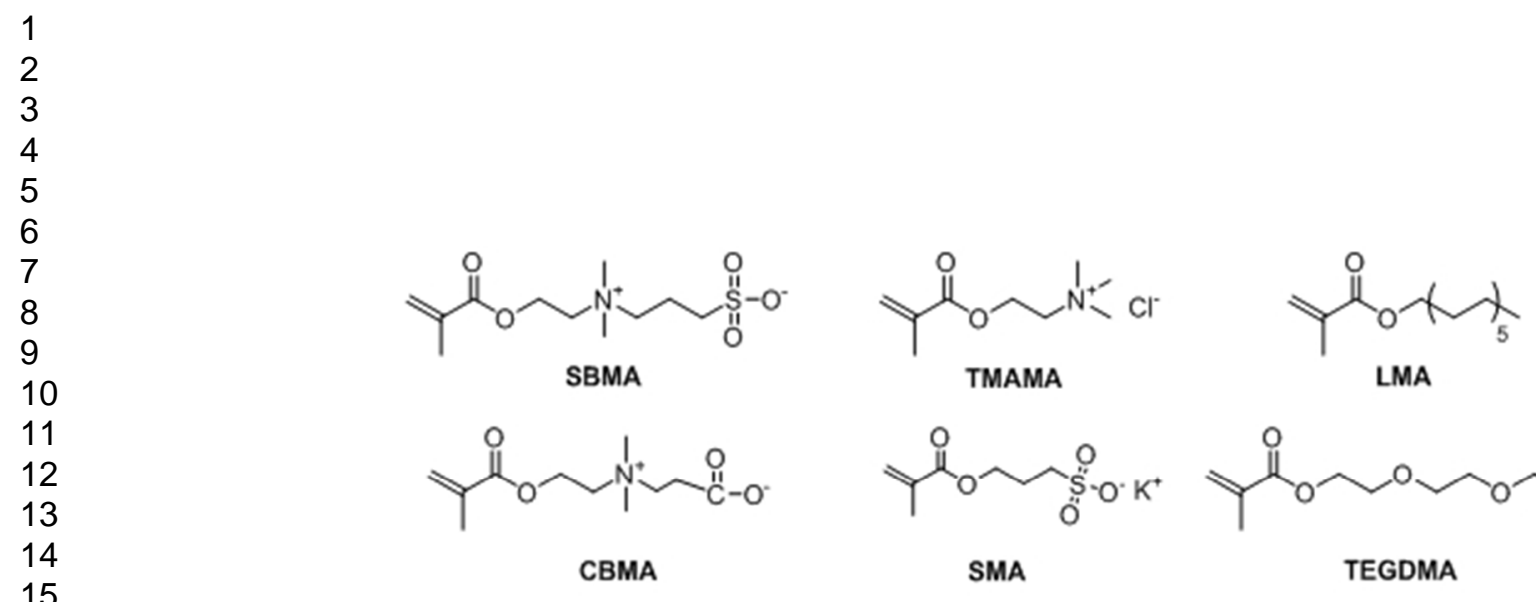

Figure 1. Chemical structures of monomers and cross-linker selected for the preparation of the (pseudo)zwitterionic hydrogel coatings.

$142 \times 38 \mathrm{~mm}(96 \times 96 \mathrm{DPI})$ 


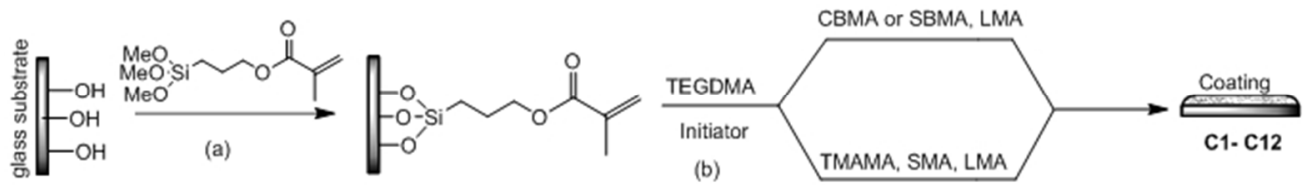

Figure 2. Preparation of zwitterionic and mixed-charge polymer coatings on glass substrates using LMA, TEGDMA and zwitterionic monomers SBMA or CBMA, or a combination of positively and negatively charged monomers SMA and TMAMA. Reaction conditions: (a) EtOH, room temperature, 16 h; (b) LPO/TMA, $\mathrm{MeOH} / \mathrm{hexyl}$ acetate, room temperature, $48 \mathrm{~h}$.

$180 \times 25 \mathrm{~mm}(96 \times 96 \mathrm{DPI})$ 

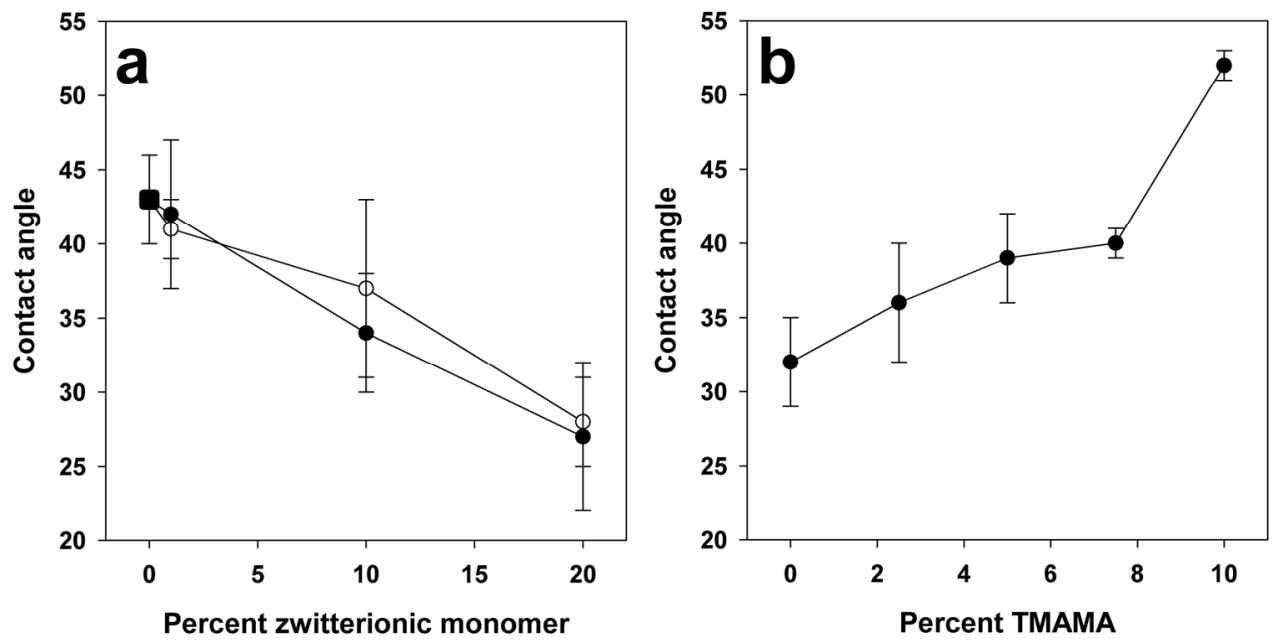

Figure 3. a) Relationship between contact angles $\left(^{\circ}\right)$ and percent content of zwitterionic monomers SBMA (white symbols, surfaces C2-C4) and CBMA (black circles, surfaces C5-C7), black square is pure LMA (C1). b) Relationship between contact angles $\left(^{\circ}\right)$ and percent content of TMAMA in coatings C8-C12. Error bars are \pm 1 S.D. $161 \times 86 \mathrm{~mm}(300 \times 300 \mathrm{DPI})$ 


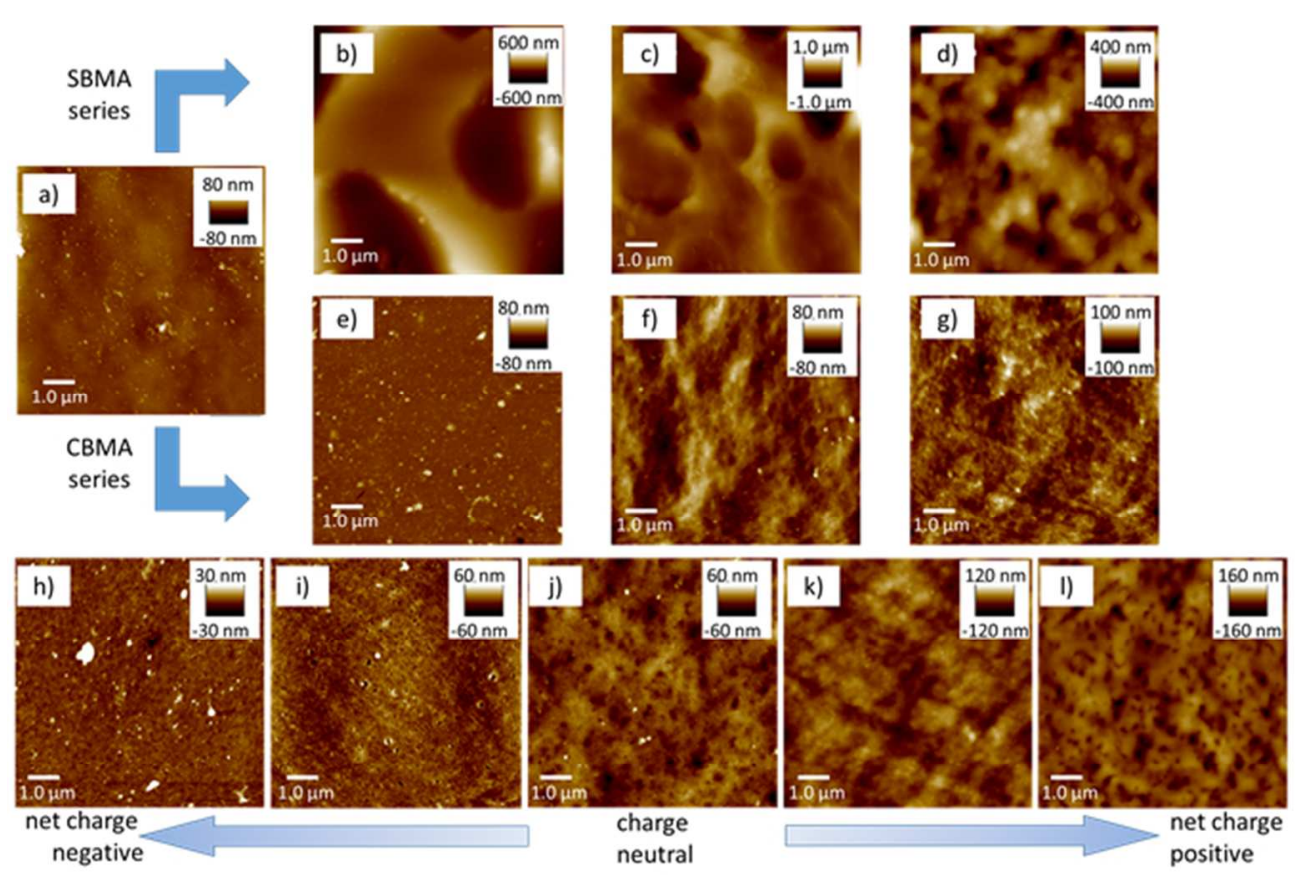

Figure 4. Representative AFM topographical images of (a) LMA coating (C1), (b-d) SBMA-containing coatings (C2-C4), (e-g) CBMA-containing coatings (C5-C7), and (h-c) the mixed-charge coatings (C8-C12).

$180 \times 119 \mathrm{~mm}(96 \times 96 \mathrm{DPI})$ 

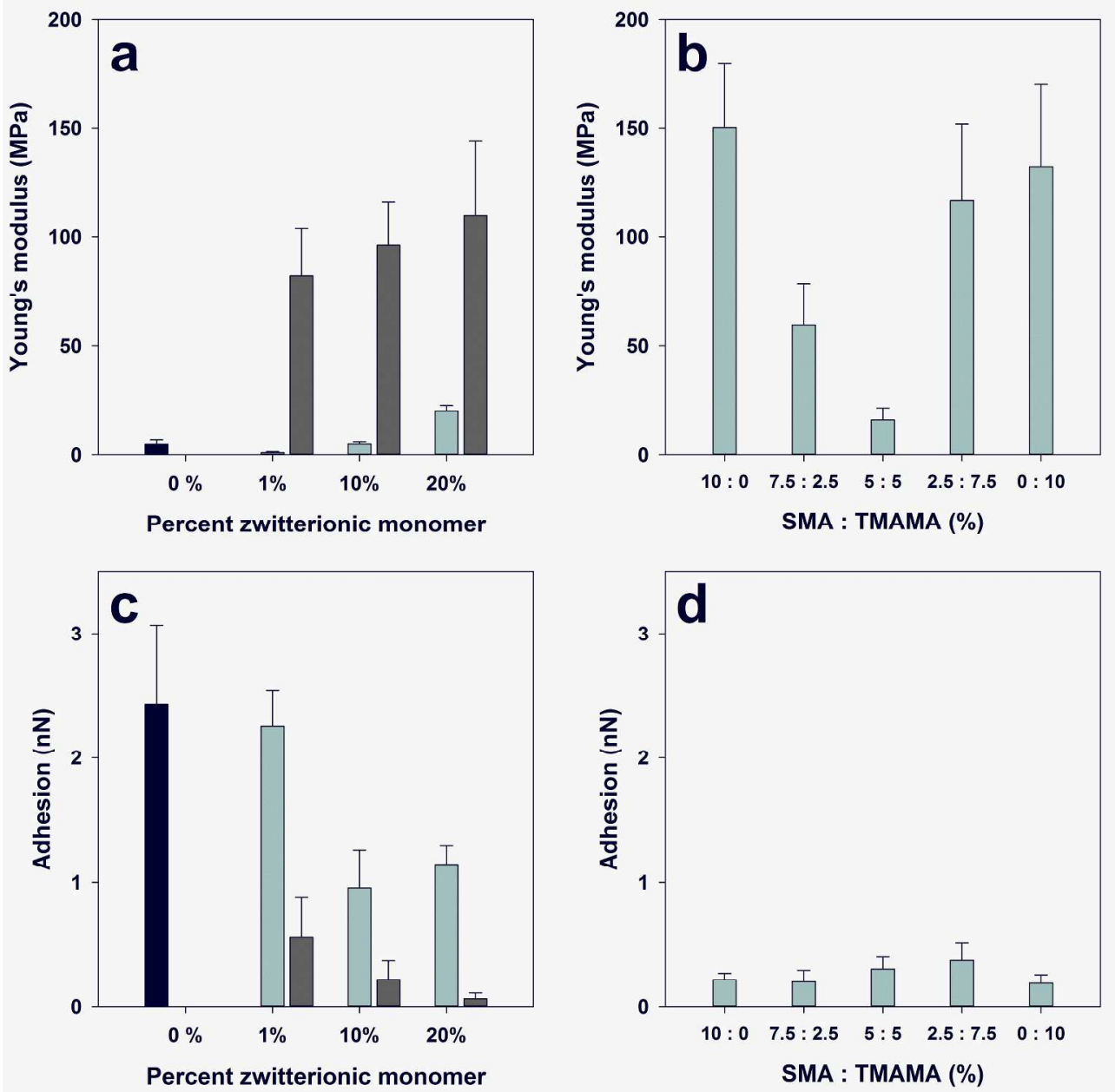

Figure 5.a) Young's modulus of LMA coating C1 (black) and as a function of SBMA content (light grey) and CBMA content (dark grey). b) Young's modulus as a function of TMAMA content in surfaces C8-C12. c) Adhesion strength of AFM tip to LMA coating C1 (black) and as a function of SBMA content (light grey) and CBMA content (dark grey). d) Adhesion strength of AFM tip as a function of TMAMA content in surfaces C8C12. Error bars are +1 S.D.

$251 \times 252 \mathrm{~mm}(300 \times 300$ DPI $)$ 

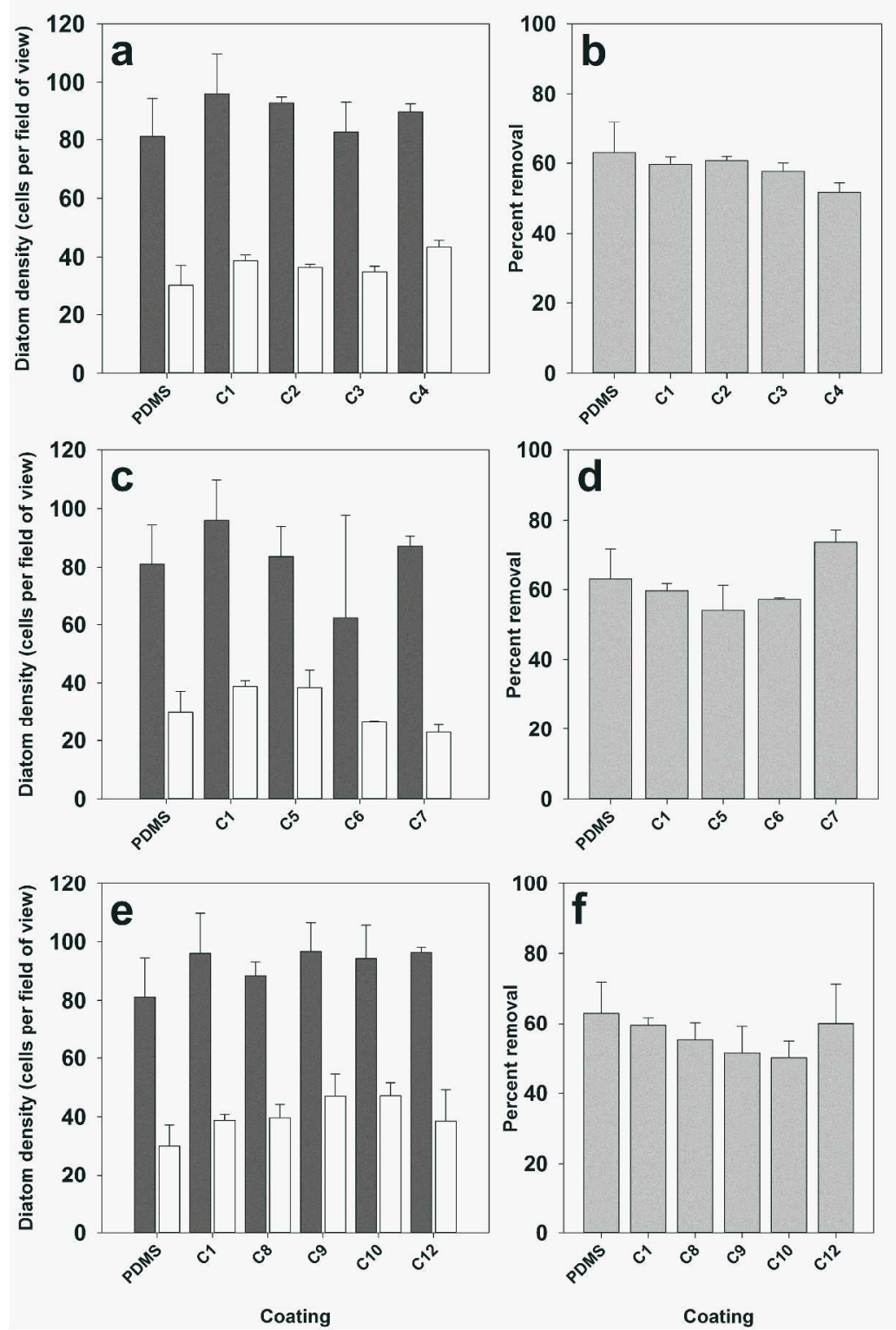

Figure 6. Performance of test coatings in adhesion and ease-of-removal assay using N. incerta. Dark grey bars show density of cells with no exposure to shear, white bars show density after exposure to $25.76 \mathrm{~Pa}$ shear stress for 5 minutes $(a, c, e)$. Light grey bars show percent removal of cells resulting from exposure to shear $(b, d, f)$. a,b) SBMA series: C1 - $100 \%$ LMA; C2 - LMA with $1 \%$ SBMA; C3 - LMA with $10 \%$ SBMA; C4; LMA with $20 \%$ SBMA. c, d) CBMA series: C1 - $100 \%$ LMA; C5 - LMA with $1 \%$ CBMA; C6 - LMA with 10\% CBMA; C7 - LMA with 20\% CBMA. e,f) Mixed charge surface series (for detailed composition data see Table 1); No data were obtained for surface C11. Error bars are +1 standard deviation.

$$
319 \times 481 \mathrm{~mm} \text { ( } 300 \times 300 \text { DPI) }
$$



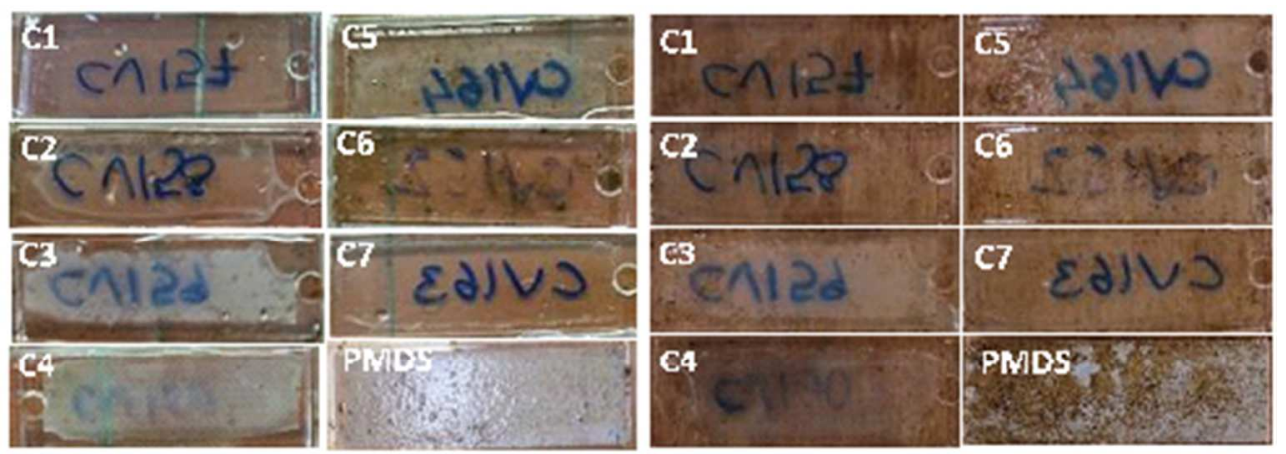

Figure 7. Coatings $\mathrm{C} 1-\mathrm{C} 7$ and polydimethyl siloxane (PDMS) standards after two weeks (left) and seven weeks (right) seawater immersion in the 'slime farm'. Slides have not been exposed to shear.

$129 \times 47 \mathrm{~mm}(96 \times 96 \mathrm{DPI})$ 


\section{Marine antifouling performance of polymer coatings incorporating zwitterions}

Supporting Information

Claudia Ventura ${ }^{I}$, Andrew J Guerin ${ }^{2}$, Osama El-Zubir ${ }^{1}$, Antonio J Ruiz-Sanchez ${ }^{l}$, Luke I Dixon ${ }^{l}$, Kevin J Reynolds ${ }^{3}$, Marie Dale ${ }^{3}$, James Ferguson ${ }^{3}$, Andrew Houlton ${ }^{1}$, Benjamin R Horrocks ${ }^{1}$, Anthony $S$ Clare $^{2}$ and David A Fulton ${ }^{1}$

${ }^{1}$ Chemical Nanoscience Laboratory, School of Chemistry, Newcastle University, Newcastle upon Tyne, NE1 7RU, UK.

${ }^{2}$ School of Marine Science and Technology, Newcastle University, Newcastle upon Tyne, NE1 7RU, UK.

${ }^{3}$ International Paint Ltd., Stoneygate Lane, Felling, Gateshead, NE10 0JY, UK.
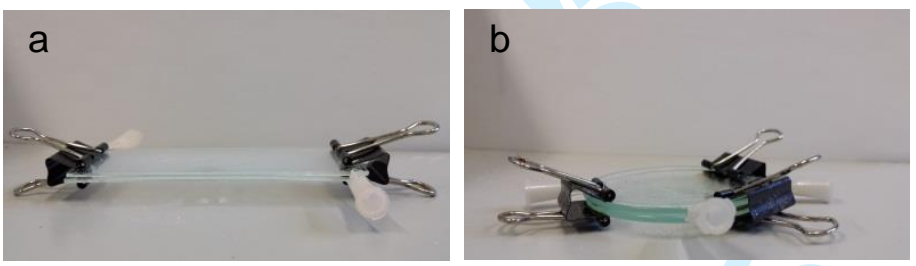

Figure S1 Photographs of the 'sandwich' system used to prepare LMA-based coatings. Two glass microscope slides (image a) or two identical watch glasses (image b) are separated by 0.31 diameter gauge syringe needles (30 gauge) and the entire assembly clamped together with clips. The bottom plate of each 'sandwich' was functionalized in order to covalently bond the coating to the glass, whilst the top plate is non-functionalized and is removed upon completion of the polymerization, leaving the polymer coating attached to the lower glass substrate. 
Table S1 Results of elemental analysis of coatings C1-C12. The results of an elemental analysis for carbon, hydrogen and nitrogen are regarded as acceptable if the accuracy of the results is within \pm $0.3 \%$ of the calculated value.

\begin{tabular}{ccccccccc}
\hline Coating & $\begin{array}{c}\text { Calculated } \\
\% \mathrm{C}\end{array}$ & $\begin{array}{c}\text { Measured } \\
\% \mathrm{C}\end{array}$ & $\begin{array}{c}\text { Calculated } \\
\% \mathrm{H}\end{array}$ & $\begin{array}{c}\text { Measured } \\
\% \mathrm{H}\end{array}$ & $\begin{array}{c}\text { Calculated } \\
\% \mathrm{~N}\end{array}$ & $\begin{array}{c}\text { Measured } \\
\% \mathrm{~N}\end{array}$ & $\begin{array}{c}\% \\
\text { Water }^{\mathrm{a}}\end{array}$ & $\begin{array}{c}\text { Swelling } \\
\text { ratio }(Q)^{\mathrm{b}}\end{array}$ \\
\hline C1 & 72.66 & 72.61 & 11.25 & 11.07 & $\mathrm{n} / \mathrm{a}$ & $\mathrm{n} / \mathrm{a}$ & 43.70 & 1.78 \\
$\mathbf{C 2}$ & 72.40 & 72.22 & 11.22 & 11.00 & 0.05 & 0.10 & 54.66 & 2.21 \\
$\mathbf{C 3}$ & 70.12 & 70.39 & 10.87 & 10.78 & 0.46 & 0.56 & 38.94 & 1.64 \\
$\mathbf{C 4}$ & 67.61 & 67.48 & 10.49 & 10.76 & 0.90 & 0.76 & 52.49 & 2.10 \\
C5 & 72.52 & 72.26 & 11.23 & 11.38 & 0.05 & 0.10 & 42.46 & 1.74 \\
C6 & 71.28 & 71.36 & 10.98 & 10.78 & 0.46 & 0.50 & 31.27 & 1.45 \\
C7 & 69.87 & 70.07 & 10.70 & 10.59 & 0.94 & 0.91 & 31.13 & 1.45 \\
C8 & 68.64 & 68.60 & 10.75 & 10.89 & $\mathrm{n} / \mathrm{a}$ & $\mathrm{n} / \mathrm{a}$ & 8.14 & 1.09 \\
C9 & 70.19 & 70.41 & 10.92 & 10.77 & 0.10 & 0.41 & 8.27 & 1.09 \\
C10 & 69.73 & 69.50 & 10.77 & 10.99 & 0.23 & 0.45 & 33.39 & 1.50 \\
C11 & 69.94 & 69.76 & 10.84 & 10.58 & 0.36 & 0.52 & 18.67 & 1.29 \\
C12 & 70.16 & 70.14 & 10.90 & 11.17 & 0.47 & 0.61 & 12.76 & 1.15 \\
\hline
\end{tabular}

${ }^{a}$ Determined by drying sample in a vacuum desiccator over $\mathrm{P}_{2} \mathrm{O}_{5}$ until constant weight is obtained. ${ }^{\mathrm{b}}$ Swelling ratio calculated from $Q=$ mass of coating after overnight immersion in water/mass of dried sample. 
Figure S2. FTIR spectra of zwitterionic coatings composed of LMA and SBMA (C1 blue line; C2 orange line; C3yellow line; $\mathrm{C} 4$ green line). The FTIR spectra are dominated by the signals for LMA with sulfonate-related bands are visible near $1040 \mathrm{~cm}^{-1}$ (within black rectangle).

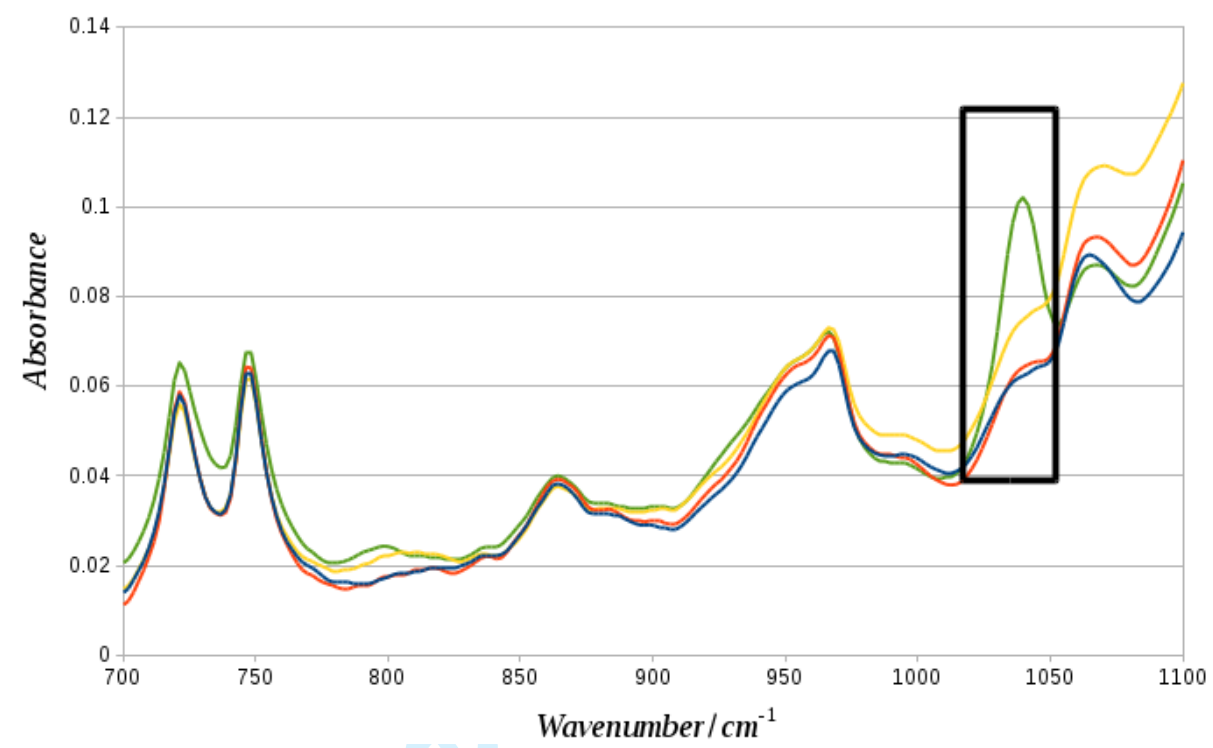

Figure S3. FTIR spectra of pseudo-zwitterionic coatings (C8 green line; C9 yellow line; $\mathrm{C} 10$ orange line) comprising LMA (90\%) and various ratios of SMA and TMAMA comonomers (10\%). The FTIR spectra are dominated by the peaks for LMA with sulfonate-related bands are visible near 1060 $\mathrm{cm}^{-1}$ (within black rectangle). The composition of the samples was 5\% SMA (orange), 7.5\% SMA (yellow and 10\% SMA (green). Smaller fractions of sulfonate give spectra that are difficult to distinguish from lauryl methacrylate.

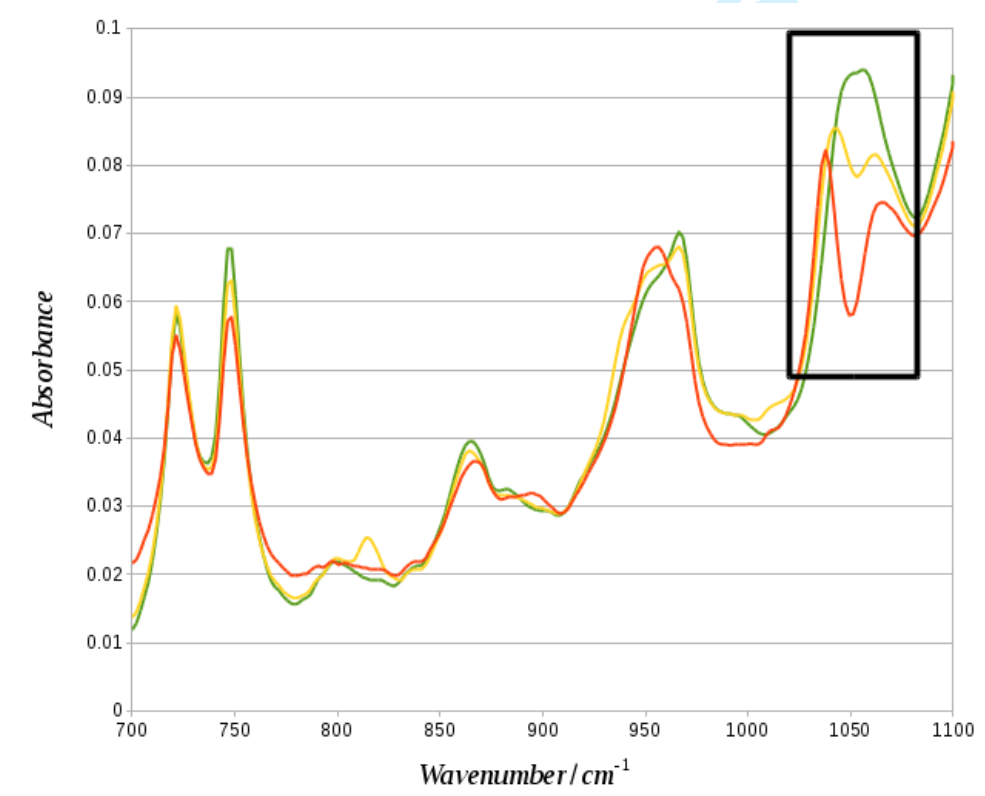




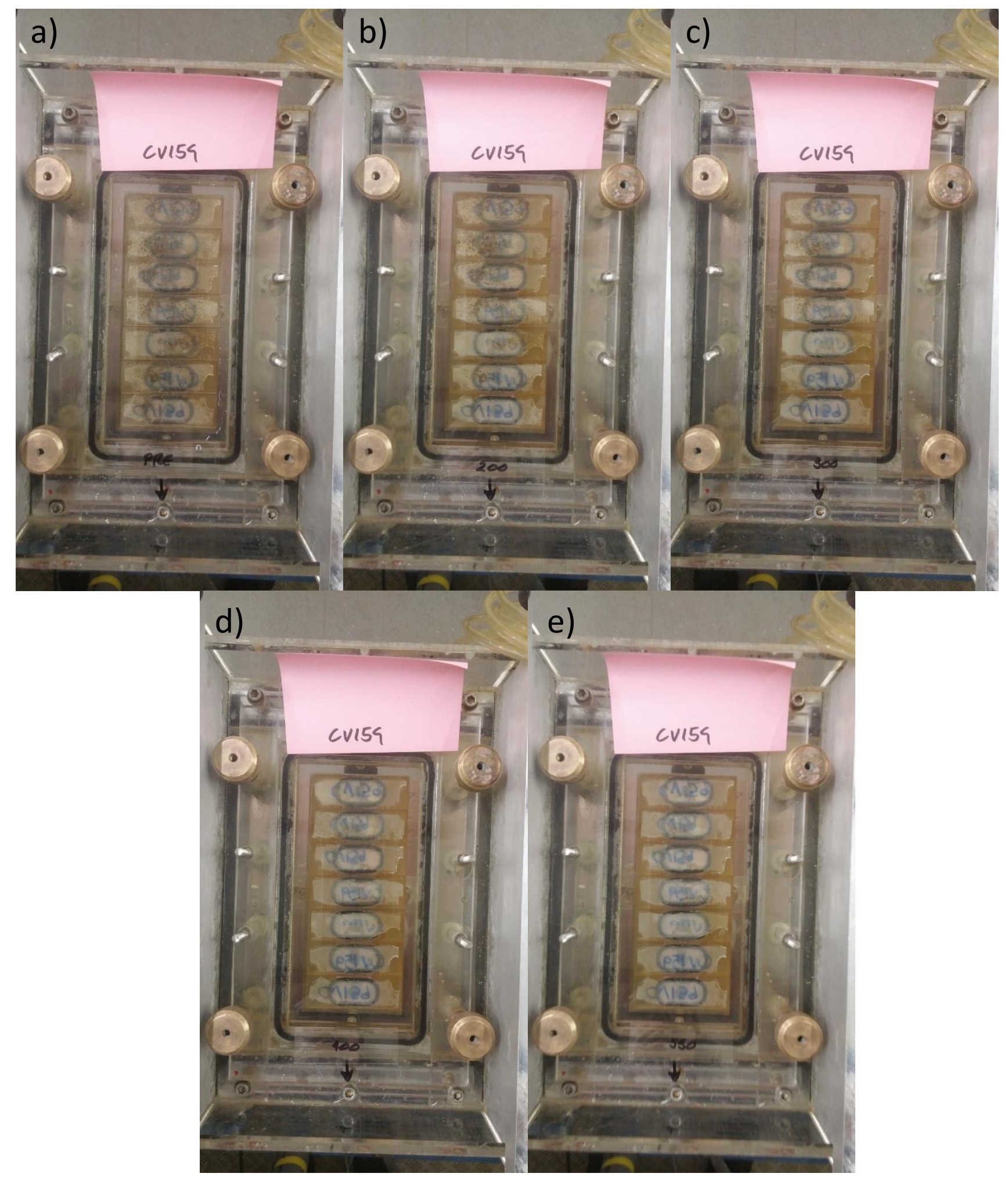

Figure S4 Removal images for coating C3 at pump speeds a) 0, b) 200, c) 300, d) 400 and e) 550. These values represent the pump speeds corresponding to water flow speeds within the flume of $0,1.4,2.0,2.4 \mathrm{~m} / \mathrm{s}$, respectively. 


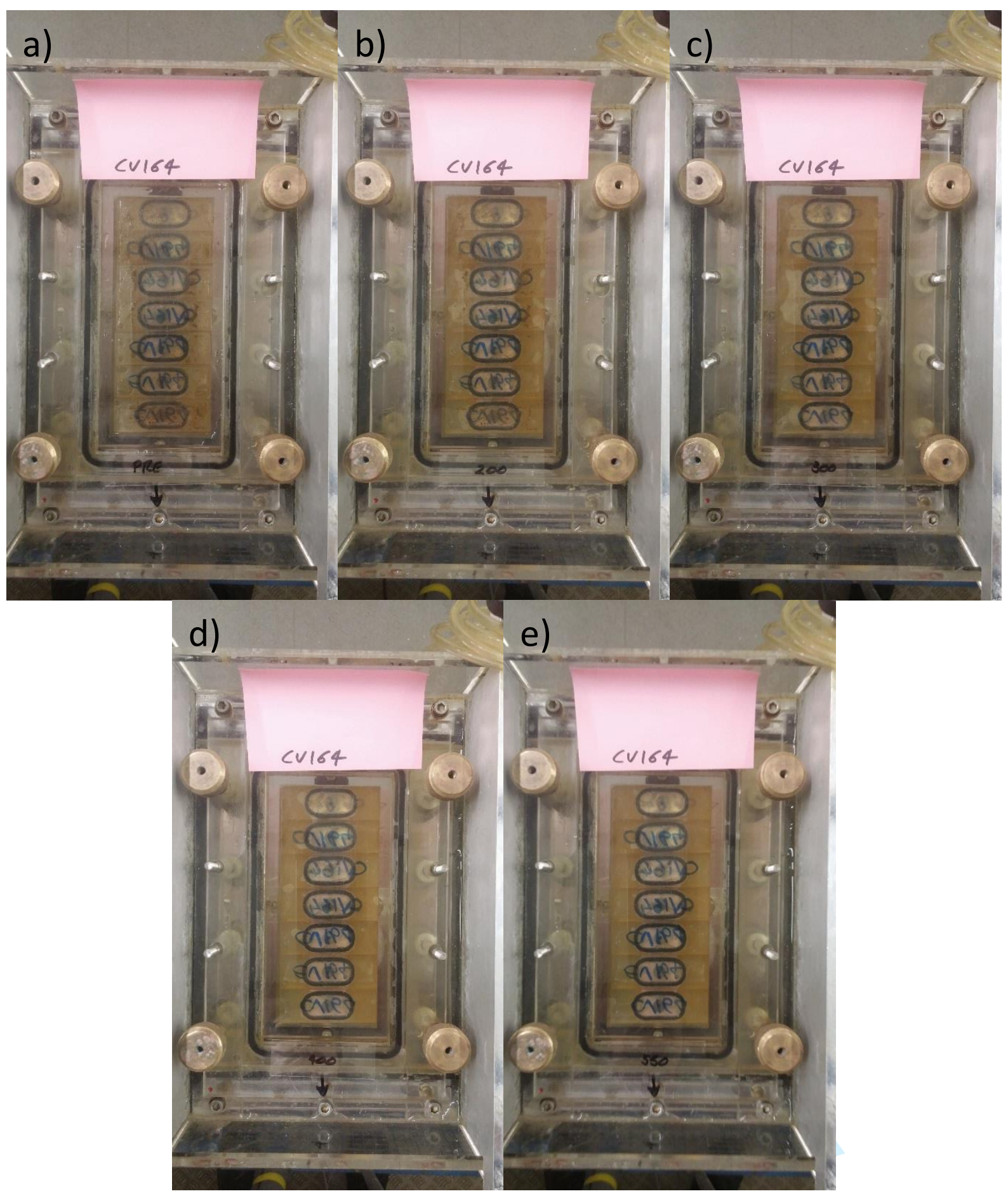

Figure S5 Removal images for C5 at pump speeds a) 0, b) 200, c) 300, d) 400 and e) 550. These values represent the pump speeds corresponding to water flow speeds within the flume of $0,1.4,2.0,2.4 \mathrm{~m} / \mathrm{s}$, respectively. 


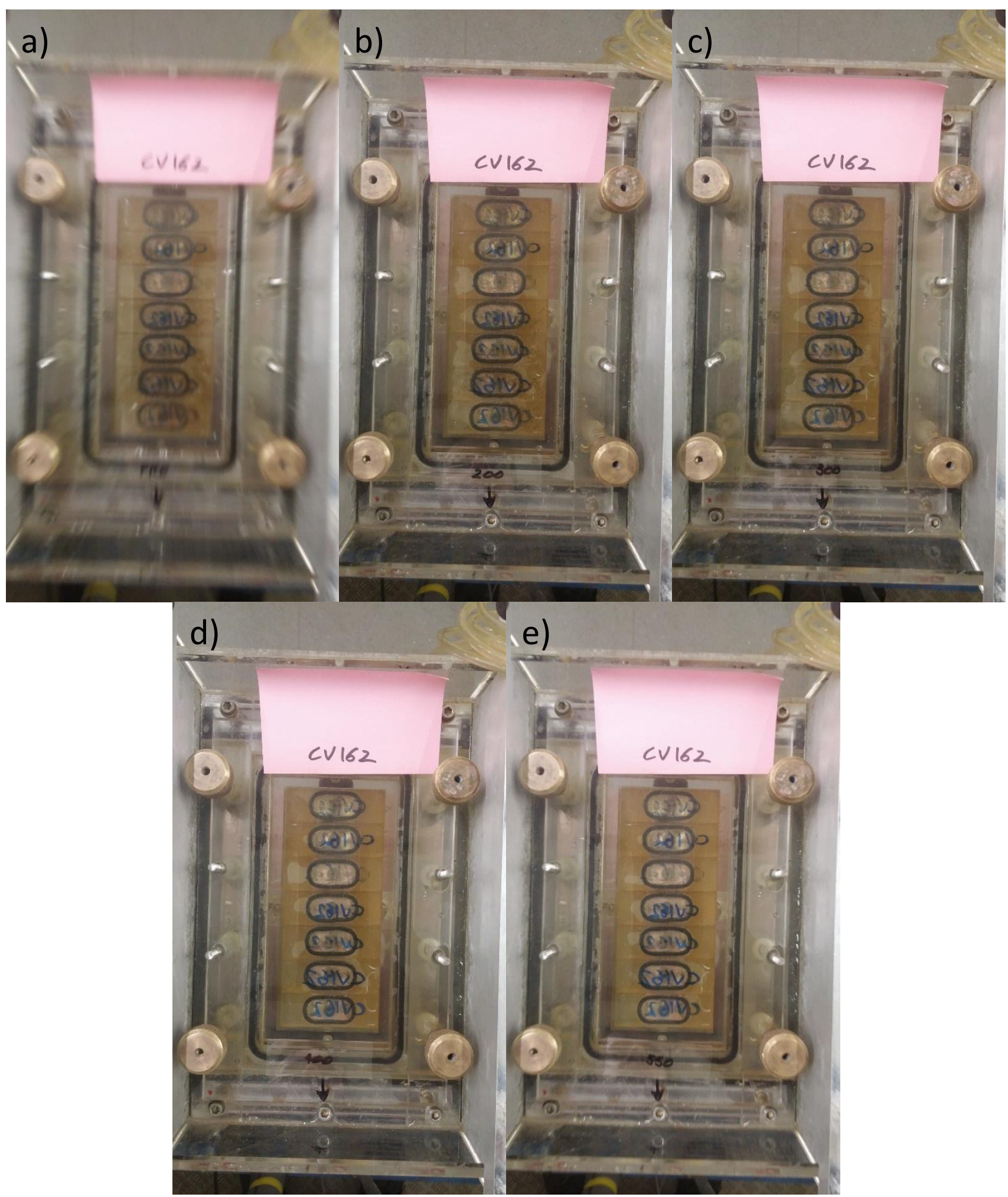

Figure S6 Removal images for C6 at pump speeds a) 0, b) 200, c) 300, d) 400 and e) 550. These values represent the pump speeds corresponding to water flow speeds within the flume of $0,1.4,2.0,2.4 \mathrm{~m} / \mathrm{s}$, respectively. 


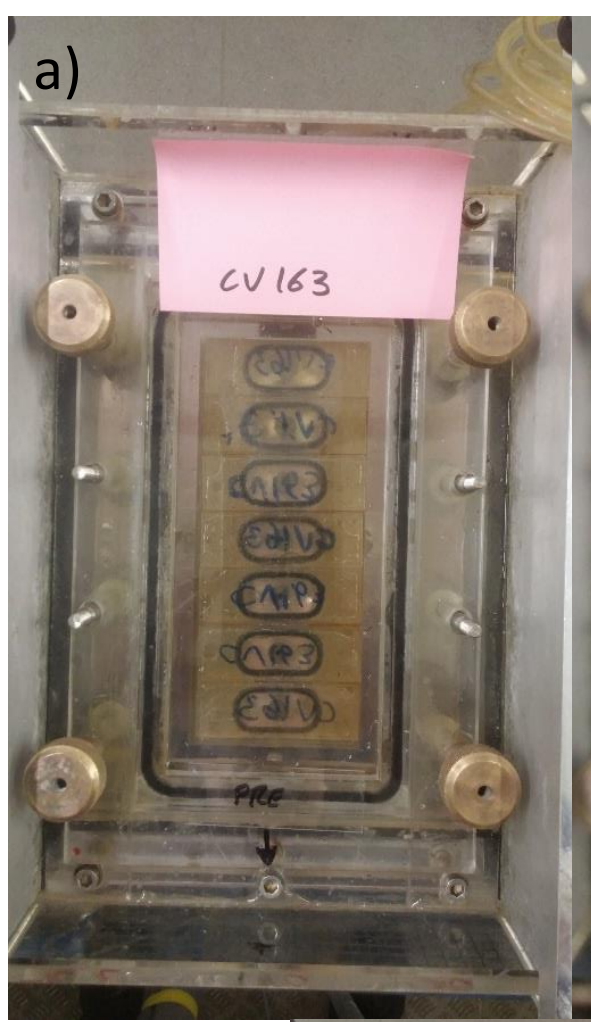

b)

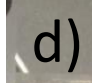

d)

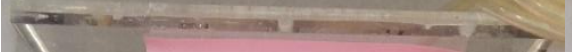

e) c)
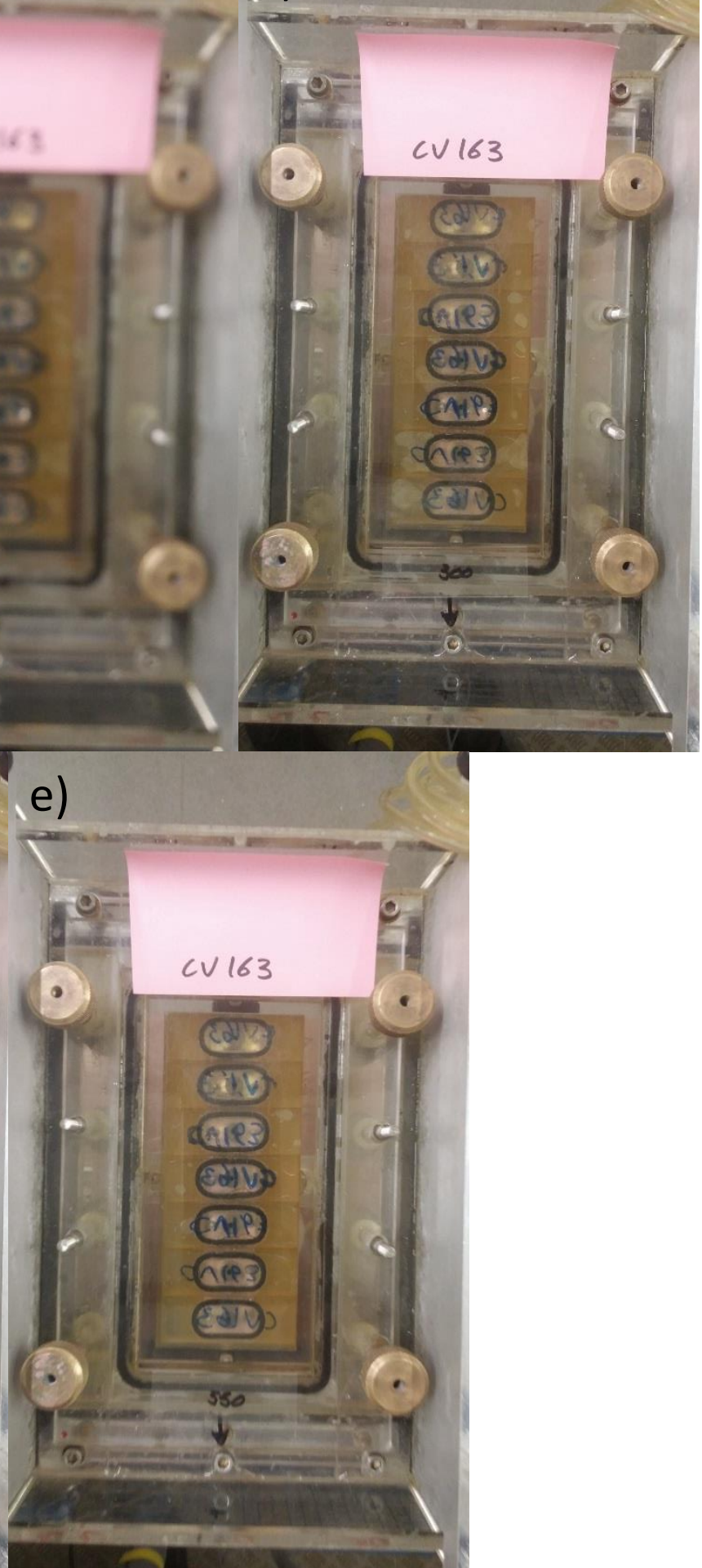

Figure S7 Removal images for C7 at pump speeds a) 0, b) 200, c) 300, d) 400 and e) 550. These values represent the pump speeds corresponding to water flow speeds within the flume of $0,1.4,2.0,2.4 \mathrm{~m} / \mathrm{s}$, respectively. 


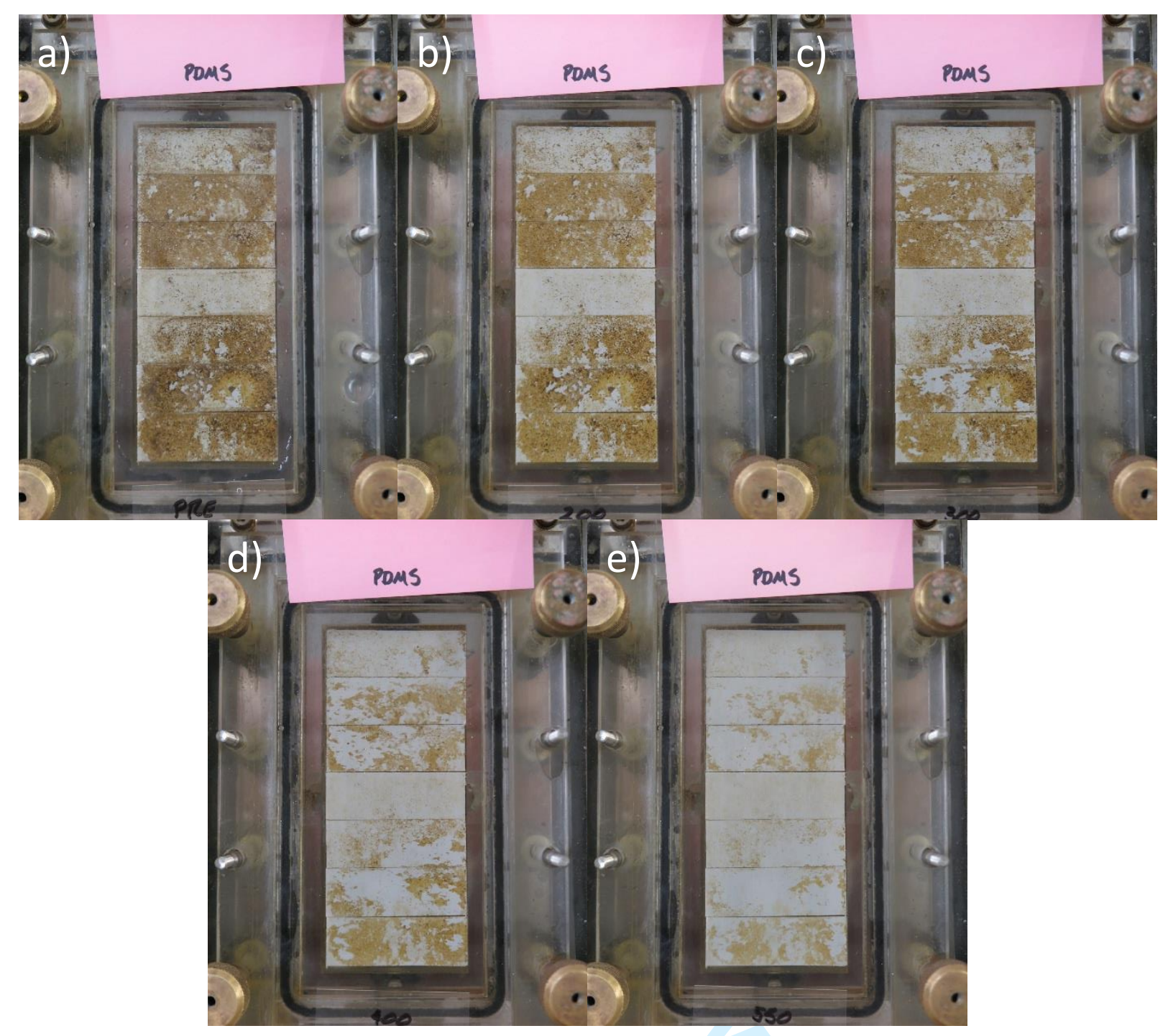

Figure S8 Removal images for PMDS standard at pump speeds a) 0, b) 200, c) 300, d) 400 and e) 550. These values represent the pump speeds corresponding to water flow speeds within the flume of $0,1.4,2.0,2.4 \mathrm{~m} / \mathrm{s}$, respectively. 